\title{
Peligro Sísmico en el Bloque de Jalisco, México
}

\author{
F. J. NÚÑEZ CORNÚ \\ Centro de Sismología y Vulcanología de Occidente, Universidad de Guadalajara \\ Puerto Vallarta, Jalisco, México. \\ pacornu77@gmail.com
}

Recibido: 20/07/2011

Aceptado: 25/07/2011

\section{Resumen}

En la región del Bloque de Jalisco en el occidente de México se han registrado históricamente grandes terremotos muy destructivos, acompañados en algunos casos de tsunamis. En este trabajo se hace una revisión y reevaluación de la localización de los terremotos a partir los datos históricos disponibles. Así mismo se revisan los principales estudios sismológicos realizados recientemente. Como resultado se concluye que el Peligro Sísmico es muy alto en toda la región y esto requiere de un estudio continuo y sistemático. Aunque aparentemente la zona de más Peligro Sísmico al presente es la Costa Norte de Jalisco, no se pueden descartar la ocurrencia de terremotos de magnitud media $(6.9<\mathrm{M}<7.4)$ en el corto y mediano plazo en el resto de la región

Palabras clave: Peligros naturales, peligro sísmico, terremotos, tsunamis, volcanes.

\begin{abstract}
Historically large and very destructive earthquakes as well as tsunamis occurred along the Jalisco Block at the west part of Mexico. Using available historic data and recent seismic studies, we revise and reevaluate the localization of these earthquakes. We conclude that exists high seismic hazard, therefore it is necessary a systematic and continuous study of the seismicity along the area. The north shore of Jalisco present the highest seismic hazard, nevertheless we cannot ignore medium earthquakes $(6.9<\mathrm{M}<7.4)$ that occurs along the rest of the region.
\end{abstract}

Seismic Hazard at Jalisco Block, Mexico

Keywords: Natural hazards, seismic hazard, earthquakes, tsunamis, volcanoes.

Sumario: Introducción. 1. Antecedentes. 1.1. Marco Tectónico. 1.2. El Bloque de Jalisco. 1.3 Sismicidad. 2. Estudios Recientes. 2.1. CORTES P96. 2.2. Estudios 1996 - 1998. 2.2.1. Región de la Costa. 2.2.2. Región de Bahía de Banderas. 2.2.2.1 Zona norte de la Bahía. 2.2.2.2. Zona centro de la Bahía. 2.2.2.3. Zona sur de la Bahía. 2.2.3. Región de Amatlán de Cañas. 2.2.4. Modelo. 2.3. Estudios $2000-$ 2003. 2.4. El Terremoto de Armería (22 enero 2003). 3. Conclusiones. Referencias bibliográficas.

\section{Referencia normalizada}

Núñez Cornú, F. J., (2011). Peligro Sísmico en el Bloque de Jalisco, México. Física de la Tierra Vol. 23 Núm. 1 (2011): 199-229

\section{Introducción}

La única manera de prevenir la ocurrencia desastres causados por peligros naturales es por medio de su caracterización y estudio que permitan tomar medidas preventivas, o en su caso de mitigación de posibles escenarios de desastre. El estado de Jalisco es una de las regiones con más alta sismicidad en México y por ende donde el peligro sísmico es muy alto, este peligro no solo está asociado al proceso de subducción de la Placa de Rivera bajo la Placa de Norteamérica, sino también a 
otras estructuras continentales no identificadas que han generado grandes terremotos históricos, algunos de ellos capaces de generar tsunamis. El primer paso evaluar el peligro sísmico es estudiar la sismicidad histórica y correlacionarla con la actual y los estudios recientes relacionados llevados a cabo en la región; desafortunadamente no se tiene aún una red sísmica local. El propósito de este trabajo es revisar y evaluar la sismicidad histórica, y los estudios de sismicidad recientes.

\section{Antecedentes}

El origen de la alta sismicidad en la región de Jalisco se debe a su compleja Tectónica resultado de la interacción de tres placas. Para un conocimiento general de la situación tectónica del Occidente de la Republica Mexicana se realiza una descripción de norte a sur del marco tectónico del país con relación a los límites de las placas oceánicas y el continente Norteamericano. Las características relevantes se exponen a continuación.

\subsection{Marco Tectónico}

En el Mar de Cortés (Golfo de California) actúa un sistema de fallas transformantes dando lugar a las dorsales que separa la península de Baja California, en la placa del Pacífico, del continente Norteamericano en la Placa de Norteamérica. Este sistema de fallas es la prolongación de la falla de Cerro Prieto (que continua al sistema de fallas de San Andrés en dirección sur). En la trinchera Mesoamericana subducen las placas oceánicas de Rivera y Cocos bajo el continente. En la zona de Benioff de esta trinchera y debido a este fenómeno de subducción, ocurren los mayores sismos destructivos en México.

Al sur de la boca del Mar de Cortés y separado por la zona de fracturas de Tamayo se encuentra la placa de Rivera. Esta se genera en uno de los segmentos de la dorsal del Pacífico Oriental (EPR) y subduce, en su porción sureste, en la trinchera Mesoamericana, bajo la estructura conocida como el Bloque de Jalisco y que incluye territorios de los estados de Jalisco, Colima, Nayarit y parte de Michoacán. En su borde suroeste la placa de Rivera está separada de la placa del Pacífico por la zona de fractura de Rivera (RFZ). En la parte oriental de esta zona de fractura se encuentra el límite de placas entre Rivera y Cocos. Este límite entre ambas placas oceánicas está aún sin definir, no se conoce con seguridad ni la región de contacto, ni el movimiento relativo entre ambas placas. Relacionado con la subducción de las placas, de Rivera y de Cocos, se formó en el Mioceno superior el eje Neovolcánico Mexicano que se extiende desde el golfo de California, o Mar de Cortés, hasta el golfo de México, con una orientación aproximada este-oeste. 


\subsection{El Bloque de Jalisco}

El Bloque de Jalisco (Figura 1), es la estructura bajo la que subduce la placa de Rivera, está delimitado por la Trinchera Mesoamericana hacia occidente, la zona del graben de Colima en la parte meridional y la zona del graben de Tepic-Zacoalco en la parte oriental, mientras que el borde septentrional no ha sido delimitado con precisión.

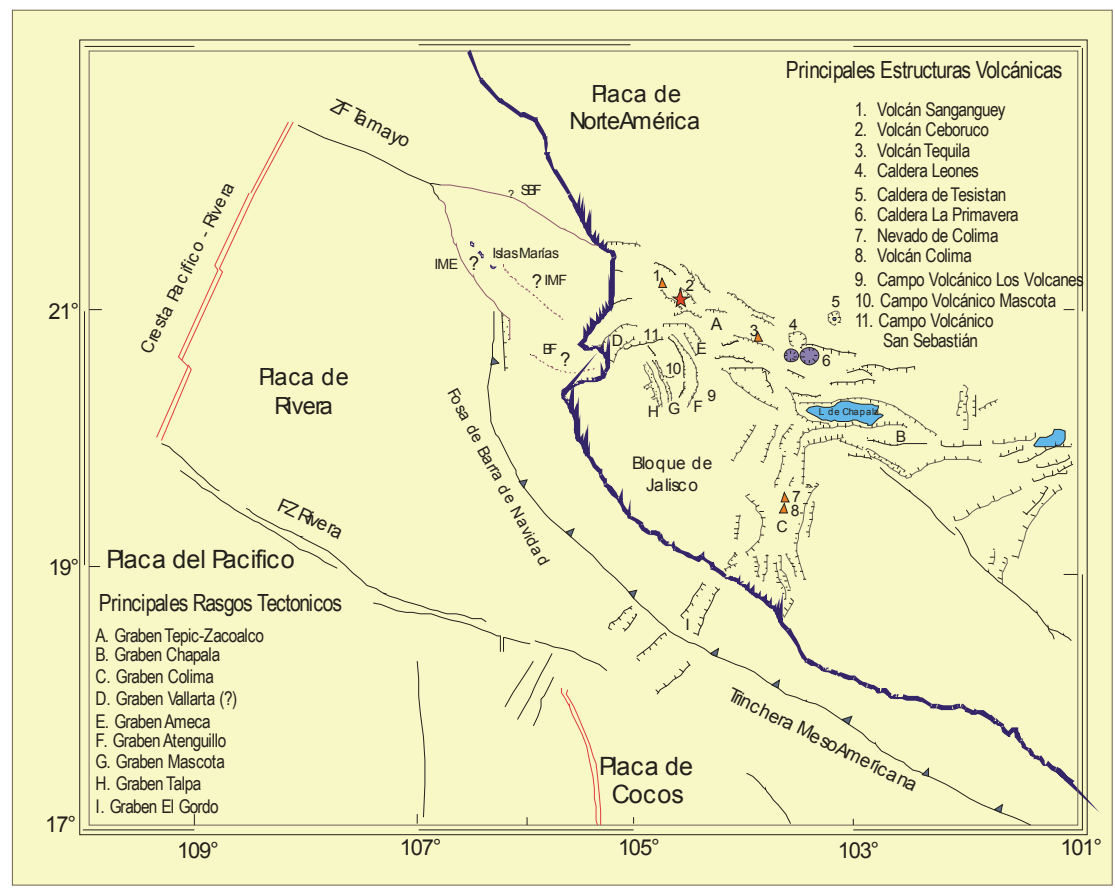

Fig. 1. Marco tectónico del Bloque de Jalisco. Se señalan con detalle las características tectónicas y volcánicas principales

Los centros volcánicos Cuaternarios en el oeste del eje Neovolcánico están confinados en tres estructuras extensionales, que se intersectan a $50 \mathrm{~km}$ al suroeste de la ciudad de Guadalajara en un "punto triple". Este punto triple ha evolucionado desde el Plioceno y, siguiendo la tendencia general del eje Neovolcánico, presenta una migración hacia el sur. Estas estructuras extensionales delimitan el Bloque de Jalisco y son:

- El graben de Colima al Este,

- El graben de Chapala, que forma un brazo con orientación Este

- El graben de Tepic-Zacoalco, que representa el límite noreste del bloque de Jalisco, siendo los ángulos de separación entre los tres graben de $100^{\circ}, 115$ 
y $145^{\circ}$, medidos en sentido contrario a las agujas del reloj y desde el graben de Colima (ver figura 1).

En el área de los tres graben son dominantes las andesitas, calcoalcalinas y rocas relacionadas, típicas de los arcos volcánicos de subducción. En el graben de Colima y graben de Tepic-Zacoalco magmas alcalinos han erupcionado contemporáneamente con magmas calcoalcalinos desde el Plioceno. Los magmas alcalinos son raros en zonas de subducción, pero frecuentes en zonas de fracturación (rifting) continental.

Las principales estructuras tectónicas continentales que se observan en el Bloque de Jalisco son:

- Graben de Colima

- Graben de Tepic-Zacoalco

- Graben de Chapala

- Río Verde - San Cristóbal de la Cañada

\subsection{Sismicidad}

La región de Jalisco es una de las zonas sísmicas más activas en México, las principales unidades tectónicas en esta región son el Bloque de Jalisco y la Placa de Rivera, que subduce bajo el Bloque. El mayor terremoto $(\mathrm{M}=8.2)$ ocurrido en México en el siglo XX (1932) tuvo lugar en la costa de Jalisco, este fue seguido por otro de magnitud 7.8 quince días después. En 1995 un terremoto de magnitud 8.0 ocurrió en la costa de Jalisco, pero su área de ruptura fue solo la mitad sur del área propuesta para los terremotos de 1932, esto sugiere que la costa norte de Jalisco, incluyendo Bahía de Banderas, es una zona de alto potencial sísmico (también conocida como brecha sísmica) [figura 2]. Sin embargo, no solo terremotos asociados al proceso de subducción ocurren en la región también existen grandes terremotos intraplaca como los eventos de diciembre 27 de 1568 y de febrero 11 de 1872 . En la región también existen tres volcanes activos, el Sanganguey, el Ceboruco y el más activo en México el Volcán de Fuego (también conocido como Colima o Zapotlán). Pero a pesar de esto y del riesgo asociado a estos procesos tectónicos, en la costa de Jalisco solo existía hasta el 2001, una estación sismológica permanente en Chamela perteneciente al Servicio Sismológico Nacional (SSN) y la Red Sísmica Telemétrica de Colima (RESCO) localizada sobre el Volcán y la parte sur de la Zona del graben de Colima.

En junio de 1932, los días 3 y 18 de junio, ocurrieron temblores de magnitud 8.2 y 7.8, respectivamente que rompieron toda la zona de contacto entre la Placa de Rivera y el Bloque de Jalisco, ambos generaron tsunamis importantes, aun no estudiados. Posteriormente, el día 22 de junio, se produce un tsunami que genera olas que alcanzan 20 metros de altura y causan gran destrucción y más de 30 muertos en la zona de Cuyutlán. Este tsunami ha sido asociado al deslizamiento de sedimentos del Río Armería, acumulados en la plataforma continental, hacia uno de los cañones de la Fosa Mesoamericana; los reportes históricos mezclan los daños de los tres tsunamis al ocurrir en un período de tiempo tan corto. El terremoto de 1995 
genera un tsunami en la Jalisco afectando principalmente el área de La Manzanilla alcanzado una altura máxima de $5 \mathrm{~m}$ y una distancia horizontal de inundación de un $1 \mathrm{~km}$.

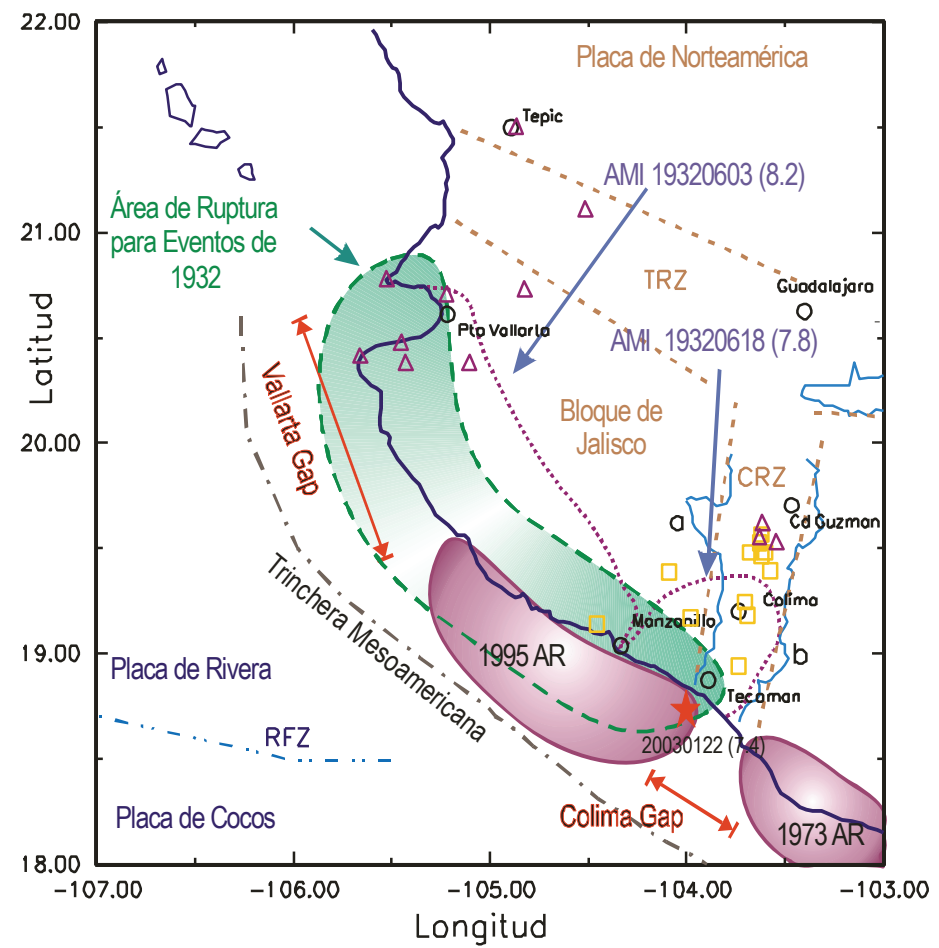

Figura 2. Mapa sismotectónico de la costa del Bloque de Jalisco, zonas de ruptura de las grandes terremotos y brechas (gaps) sísmicos existentes.

La historia macrosísmica de la región se remonta hasta 1544. En los últimos 160 años, han ocurrido 10 sismos importantes con Ms > 7.4: 11/feb./1875 Ms =7.5 (Singh et al, 1981 ) 20/ene/1900 Ms=7.9, 16/may/1900 Ms=7.4 (op. cit.), 3 y 18/jun/1932 Ms $=8.2$ y 7.8, respectivamente (op. cit.) 10/ene/1973 Ms $>7.5$ (Eissler y Mcnally, 1984), 19 y 20/sep/1985 con Ms=8.1 y 7.8, respectivamente; 9/10/95 con $\mathrm{Ms}=5.1$ (ver Tabla y figura 3). Los tiempos de recurrencia estimados por Singh et al (1985) para terremotos como los de 1932 en la costa de Jalisco es de 77 años y considerando que el temblor de 1995 rompe apenas con la mitad sur del área que se rompió en 1932, la posibilidad de que ocurra un evento similar al de 1995 en un período relativamente corto de tiempo es muy alta (Figura 2). El 22 de enero del 2003 ocurre un terremoto somero de $\mathrm{Mw}=7.4$ en la costa de Armería no asociado al proceso de subducción (Núñez-Cornú et al, 2004). Por otra parte la complejidad de esta región tectónica se refleja en la existencia de estructuras desconocidas o no estudiadas capaces de generar terremotos de magnitud media (7.0 - 7.6) como el 
ocurrido cerca de las Islas Marías, donde causó gran destrucción, el 3 de diciembre de $1948(\mathrm{M}=7.0)$, estos dos últimos terremotos pueden estar relacionados con una subducción oblicua.

Tabla. 1. Relación de sismos históricos importantes en el Bloque de Jalisco.

\begin{tabular}{|c|c|c|}
\hline & \multicolumn{2}{|r|}{ Sismos Históricos en el Bloque de Jalisco } \\
\hline Num & Fecha & Descripción \\
\hline 1 & 1567 & $\begin{array}{l}\text { En Amacueca se derrumbó y hundió el convento e iglesia. En Zapotlán el Grande } \\
\text { (Actual Ciudad Guzmán, Jal.) cayó la primer iglesia. }\end{array}$ \\
\hline 2 & $27 / 12 / 1568$ & $\begin{array}{l}(\mathrm{M}=7.5 ?, \mathrm{I}=\mathrm{IV}) \text { Derrumbe de casas e iglesias en la rivera del lago de Chapala. } \\
\text { Hubo intensa actividad sísmica en la zona comprendida entre Zapotlán y Ameca. }\end{array}$ \\
\hline 3 & $27 / 12 / 1577$ & $\begin{array}{l}\text { (I= V) Asociado con erupción del Volcán de Colima. Muchos daños y muerte en } \\
\text { Zapotlán. En Guadalajara se desplomó la torre del templo de San Francisco. }\end{array}$ \\
\hline 4 & $15 / 04 / 1611$ & $\begin{array}{l}(\mathrm{I}=\mathrm{V}) \text { En Zapotlán y Zapotiltic fueron destruidos los conventos franciscanos. } \\
\text { Asociado a la actividad del Volcán de Colima que entró en un fuerte período } \\
\text { eruptivo el } 29 \text { de Sep. de } 1611 \text {. }\end{array}$ \\
\hline 5 & $26 / 08 / 1611$ & $\begin{array}{l}\text { (I= V) Destruye la iglesia de Zapotlán y pocos días después (30 Ago.) hubo otro } \\
\text { que derrumbó el hospital de la Purísima Concepción y otras fincas. }\end{array}$ \\
\hline 6 & $15 / 08 / 1711$ & $\begin{array}{l}(\mathrm{M}=7.5 ?, \mathrm{I}=\mathrm{IV}) \text { Gran destrucción en Amacueca, Sayula y Zapotlán. Se sintió en } \\
\text { Guadalajara. }\end{array}$ \\
\hline 7 & $22 / 10 / 1743$ & Destrucción de muchas casas en Zapotlán. \\
\hline 8 & $25 / 03 / 1806$ & $\begin{array}{l}(\mathrm{M}=7.5, \mathrm{I}=\mathrm{VI}) \text { sismo al que le siguieron intensas réplicas durante unos dos meses. } \\
\text { Fuerte destrucción en Zapotlán (más de } 200 \text { casas) incluyendo daños a la parroquia } \\
\text { y muchos muertos (más de } 280 \text { ). También hubo daños en Tuxpan, Tamazula, } \\
\text { Sayula, Autlán, Amacueca y Guadalajara (grietas en Catedral, Palacio de Gobierno } \\
\text { y otras construcciones). Hay informes erroneos de la caída de las torres de la } \\
\text { Catedral de Guadalajara. }\end{array}$ \\
\hline 9 & $31 / 05 / 1818$ & $\begin{array}{l}\text { (M=7.7, I= VI) A pesar de que su magnitud fue de } 7.7 \text { y su epicentro se localizó a } \\
\text { unos } 175 \mathrm{~km} \text { hacia el suroeste de Guadalajara, causó muchos daños y derrumbó las } \\
\text { torres originales de la Catedral y agrietó dos de sus bóvedas. No fue sino hasta el } \\
\text { período de } 1851 \text { a } 1854 \text { que se volvieron a construir las torres, y hasta la fecha han } \\
\text { perdurado. Hubo fuertes destrozos, en varias poblaciones de Jalisco (Tala, Ameca, } \\
\text { Cocula, Sta. Ana, Acatlán, Zacoalco, Sayula, Zapotlán, etc.), pero sobre todo en la } \\
\text { ciudad de Colima. }\end{array}$ \\
\hline 10 & $22 / 11 / 1837$ & $\begin{array}{l}(\mathrm{M}=7.7, \mathrm{I}=\mathrm{VI}) \text { "Temblor de Sta. Cecilia". Agrietó la fachada de la catedral de } \\
\text { Guadalajara y otras edificaciones. Se sintió también en Zapotlán y en el sur de } \\
\text { Jalisco. }\end{array}$ \\
\hline 11 & $02 / 10 / 1847$ & $\begin{array}{l}(\mathrm{M}=7, \mathrm{I}=\mathrm{V}) \text { Causó muchos derrumbes y muertes en Ocotlán, daños leves en } \\
\text { Guadalajara y Zapotlán y se sintió hasta la Cd. de México. }\end{array}$ \\
\hline 12 & $11 / 021875$ & $\begin{array}{l}\text { (M=7.5, I= VIII) Muy fuerte en San Cristobal de la Barranca, en donde derribó la } \\
\text { mayoría de las casas y causó alrededor de } 50 \text { muertos (la población era de } 800 \text { ). En } \\
\text { Guadalajara no causó muerte pero sí fracturas en muchas casas y en los siguientes } \\
\text { templos: Catedral, el Sagrario, la Merced, Santa Mónica, San Diego, Capilla de } \\
\text { Jesús, de la Compañía (actual biblioteca iberoamericana), Aranzazú, Mexicaltzin- } \\
\text { go, San Juan de Dios y San José de Analco. También hubo daños en en el Palacio } \\
\text { Municipal, el Liceo de niñas y el Instituto de Ciencias (actual preparatoria No. 1). }\end{array}$ \\
\hline
\end{tabular}




\begin{tabular}{|c|c|c|}
\hline & \multicolumn{2}{|r|}{ Sismos Históricos en el Bloque de Jalisco } \\
\hline Num & Fecha & Descripción \\
\hline & & $\begin{array}{l}\text { Es el sismo en Guadalajara posiblemente con mayor intensidad (VIII), y el epicen- } \\
\text { tro se ubicó a unos } 55 \mathrm{~km} \text { hacia el noroeste. En San Cristobal hubo fallas de taludes } \\
\text { y posible licuación. El Ceboruco presentó fumarolas y arrojó algo de cenizas que } \\
\text { cayeron la zona de Ahuacatlán Tepic, Nay. Siguieron réplicas hasta sseptiembre } \\
\text { del mismo año. }\end{array}$ \\
\hline 13 & $09 / 03 / 1875$ & $\begin{array}{l}(\mathrm{M}=7.4, \mathrm{I}=\mathrm{VI}) \text { Sismo que ocurrió en la Costa de Jalisco, por el rumbo de Autlán, } \\
\text { cerca del epicentro del terremoto de } 1932 . \text { En Guadalajara agravó los daños a } \\
\text { edificaciones causadas por el sismo del } 11 \text { de febrero y sus réplicas: los templos } \\
\text { más dañados fueron: La Merced, San Diego, Aranzazú, Mexicaltzingo, Analco y } \\
\text { Loreto. }\end{array}$ \\
\hline 14 & $22 / 03 / 1878$ & $\begin{array}{l}\text { (I= IV) Causó daños en San Cristobal y se sintió fuerte en Guadalajara. Hubo } \\
\text { réplicas leves hasta abril. }\end{array}$ \\
\hline 15 & $19 / 01 / 1900$ & $\begin{array}{l}\text { (M= 7.6, I= VII) Destructor en Colima. Hubo además daños en muchas poblacio- } \\
\text { nes de Jalisco (Ocotlán, Sayula, Zapotlán, San Gabriel, Autlán, Unión de Tula y } \\
\text { Mascota. En Guadalajara sufrieron daños la cupula de El Sagrario, los templos de } \\
\text { Sta. Ma. de Gracia, San Felipe, Santa Mónica, San Diego, Capilla de Jesús, San } \\
\text { Sebastián de Analco y Mezquitán. }\end{array}$ \\
\hline 16 & $16 / 05 / 1900$ & $\begin{array}{l}(\mathrm{M}=7.1, \mathrm{I}=\mathrm{III}) \text { Intensa réplica del sismo del } 19 \text { de enero. Se sintió en varias } \\
\text { poblaciones del sur de Jalisco hasta La Barca y Guadalajara, pero solo causó daños } \\
\text { leves en Colima y Zapotlán. }\end{array}$ \\
\hline 17 & $07 / 06 / 1911$ & $\begin{array}{l}(\mathrm{M}=7.8, \mathrm{I}=\mathrm{V}) \text { "Temblor de Madero" ya que ocurrió cuando el entró triunfante a la } \\
\text { Cd. de México. Causó daños fuertes en Zapotlán (Parroquia, Santuario, Tercera } \\
\text { Orden, Sagrado Corazón y más de mil casas) y muertes (35). También fue destruc- } \\
\text { tor en la región cercana a Zapotlán (San Sebastián, San Andrés Ixtlán, Zapotiltic, } \\
\text { Tuxpan, Tamazula, Tecalitlán, San Gabriel, etc.). }\end{array}$ \\
\hline 18 & $30 / 04 / 1921$ & $\begin{array}{l}\text { Daños en Autlán, Unión de Tula y Tuxcacuesco. Fuerte en Zacoalco y otras } \\
\text { poblaciones de Jalisco. }\end{array}$ \\
\hline 19 & $03 / 06 / 1932$ & $\begin{array}{l}\text { (Ms= 8.2, I= VI) El sismo de mayor magnitud en Mèxico en el siglo XX. Su } \\
\text { epicentro se ubicò en la Costa de Jalisco, a unos } 160 \mathrm{~km} \text { de Guadalajara. Causó } \\
\text { fuertes daños en Cihuatlán, Autlán y Mascota. Hubo réplicas fuertes (magnitudes } \\
\text { de } 4 \text { a 8) hasta al menos diciembre del mismo año. El padre Severo Díaz hizo un } \\
\text { interesante análisis (Díaz Galindo, 1932). El } 13 \text { de junio entrò en erupción el } \\
\text { Volcán de Colima. }\end{array}$ \\
\hline 20 & $18 / 06 / 1932$ & $\begin{array}{l}(\mathrm{Ms}=7.8, \mathrm{I}=\mathrm{VI}) \text { Intensa réplica del terremoto del } 3 \text { de junio. Destructor en el } \\
\text { estado de Colima, sobre todo en Tecomán y Colima. Un tsunami invadió Cuyutlán. }\end{array}$ \\
\hline 21 & $09 / 04 / 1933$ & $\begin{array}{l}(\mathrm{M}=6.5, \mathrm{I}=\mathrm{IV}) \text { daños en Tenacatita y otros lugares de la Costa de Jalisco (Autlán, } \\
\text { Purificación). Fuerte en Colima }\end{array}$ \\
\hline 22 & $30 / 11 / 1934$ & $\begin{array}{l}(\mathrm{M}=7.2, \mathrm{I}=\mathrm{IV}) \text { Muy fuerte en la Costa de Jalisco. Sentido en Puerto Vallarta, } \\
\text { Mascota y Autlán. }\end{array}$ \\
\hline
\end{tabular}




\begin{tabular}{|c|c|l|}
\hline \multirow{2}{*}{ Num } & \multicolumn{3}{|c|}{ Sismos Históricos en el Bloque de Jalisco } \\
\hline 23 & $03 / 12 / 1948$ & $(\mathrm{M}=7.0)$ Epicentro en las Islas Marías, destruyó la colonia penal. \\
\hline 24 & $30 / 01 / 1973$ & $\begin{array}{l}(\mathrm{Ms}=7.4) \text { Conocido como el Terremoto de Colima, aunque en realidad ocurrió en } \\
\text { el occidente de Michoacán, región poco poblada en esa época. }\end{array}$ \\
\hline 25 & $09 / 10 / 1995$ & $\begin{array}{l}\text { (Ms= 7.6, Mw= 8.0, I= VI) Fuerte terremoto frente a las costas de Colima y } \\
\text { Jalisco. Causó fuertes daños en las Costas de Colima y Jalisco, especialmente en } \\
\text { Manzanillo, Cihuatlán, Jaluco, Barra de Navidad, Tenacatita y Puerto Vallarta. Se } \\
\text { sintió fuerte en Guadalajara ( a 240 km del epicentro), pero causó daños menores. }\end{array}$ \\
\hline 26 & $22 / 01 / 2003$ & $\begin{array}{l}\text { (Mw=7.4,) Terremoto somero frente a la costa de Armería en Colima, fuertes } \\
\text { daños en la Cd. Colima y en localidades de Jalisco al Oeste del Volcán, su patrón } \\
\text { de daños es muy diferente al de 1995. }\end{array}$ \\
\hline
\end{tabular}

\section{Estudios Recientes}

Entre 1993 y 1995 el Centro de Investigación y Educación Superior de Ensenada (CICESE) y el Departamento de Geografía de la Universidad de Guadalajara empezaron a realizar estudios de sismicidad utilizando redes temporales de estaciones portátiles. Después del terremoto de 1995 estos estudios recibieron más apoyo y se pudieron obtener los primeros resultados regionales. 


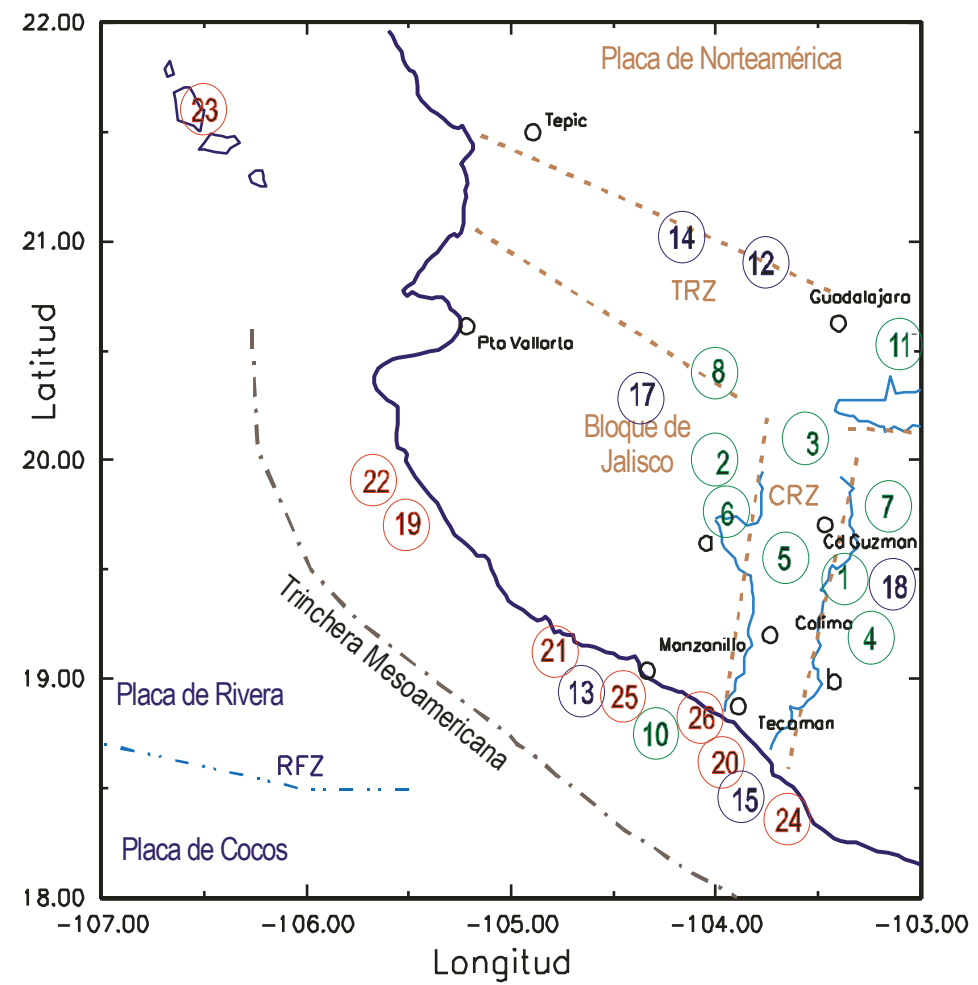

Figura 3. Mapa de sismos históricos en el Bloque de Jalisco: Color Rojo (19 - 26) tipo A, sismos instrumentales; Color azul, (12-18) tipo B, algunos datos instrumentales descripciones macrosísmicas extensas; Color verde (1-11) tipo $\mathrm{C}$, descripciones macrosísmicas limitadas.

\subsection{CORTES P96}

En 1996 el BIO Hespérides, junto con los buques Altair y Humbolt de la Armada Mexicana realizaron un estudio geofísico del Margen Oeste de México, entre $16^{\circ} \mathrm{N}$ y $30^{\circ} \mathrm{N}$ (proyecto CORTES-P96: Crustal Offshore Research Transect by Extensive Seismic Profiling) (Dañobeitia et al., 1997). En ese estudio se adquirieron datos de batimetría, con sonda multihaz, backstattering, sísmica de reflexión multicanal, sísmica de gran ángulo, con el despliegue de 40 estaciones sísmicas en tierra y campos potenciales (gravedad y magnetismo) (Figura 4). 


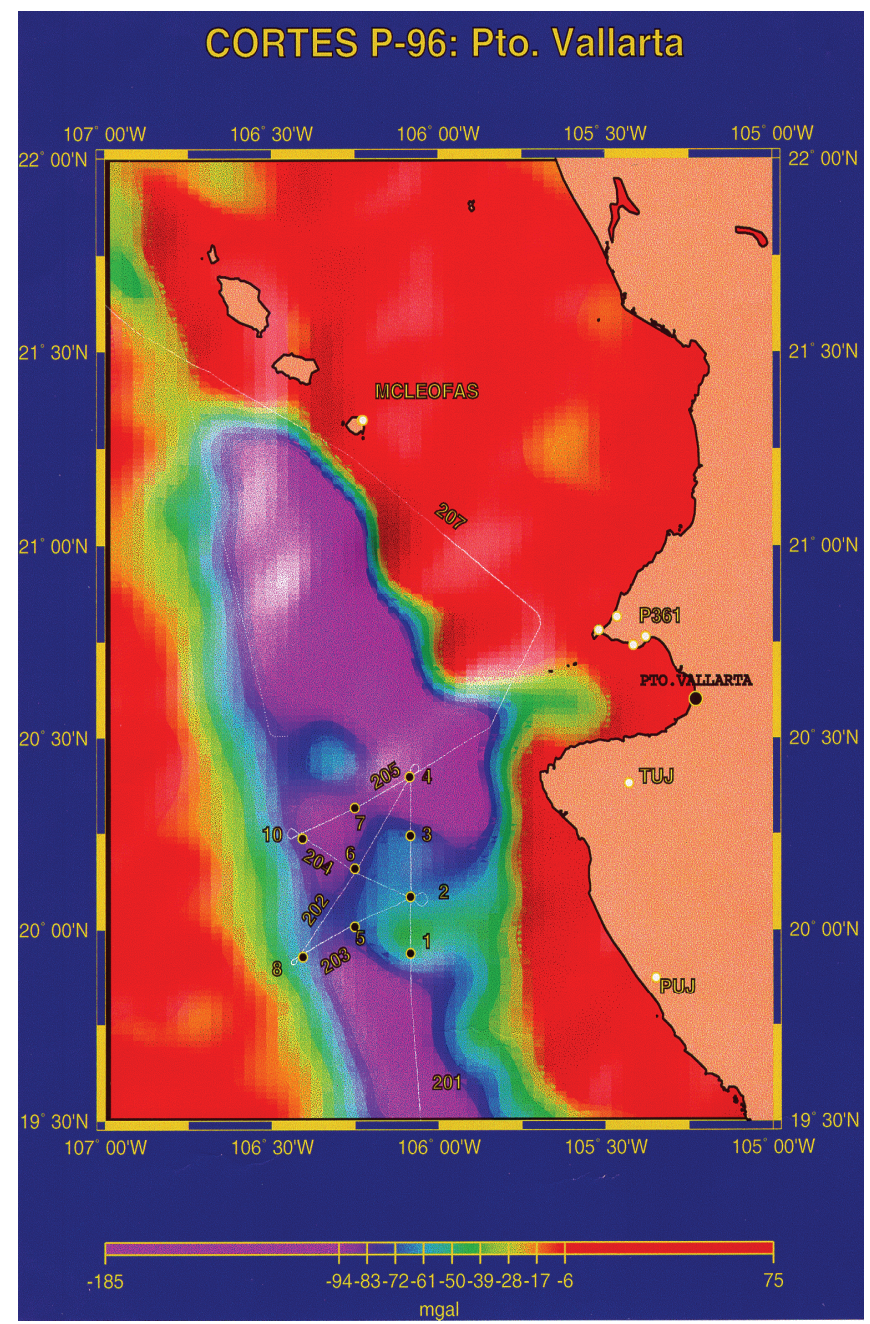

Figura 4. Mapa de transectos del Proyecto CORTES P96 frente Bahía de Banderas sobre anomalías gravimétricas oceánicas.

En la placa de Rivera se obtuvo información sobre la forma de subducción al oeste de la fosa y parcialmente, sobre el prisma de acreción (Bartolomé, 2002; Bartolomé y otros, 2011).

En el área de la Placa de Rivera, como parte del proyecto CORTES-P96, se realizaron cinco perfiles de sísmica de reflexión multicanal (perfiles 201-205, Fig. 4) alcanzado un total de $280 \mathrm{~km}$. Esos perfiles se sitúan en el dominio de subducción de la Placa de Rivera, frente a las costas de Jalisco. Como resultados más relevantes de ese estudio, se determinó que la Placa de Rivera subduce bajo la placa NA, de 
norte a sur a lo largo del eje de la fosa, con un ángulo de subducción entre $6^{\circ}$ y $8^{\circ}$. El proceso de subducción parece continuar hacia el norte, aunque no se obtuvo información sobre esta parte. Una consecuencia de esa subducción podría tener relación con el levantamiento de las islas Tres Marías (Fig. 5) (Barlolomé y otros, 2011).

Las observaciones tectónicas basadas en la interpretación de los datos de sísmica multicanal, indican la existencia de diferencias estructurales significativas desde el norte hasta el sur del paralelo $20.2^{\circ} \mathrm{N}$. En el relleno de sedimentos en la fosa, de espesor medio $2.5 \mathrm{~km}$ y existen evidencias de la existencia de fallas normales en el techo de la corteza oceánica.

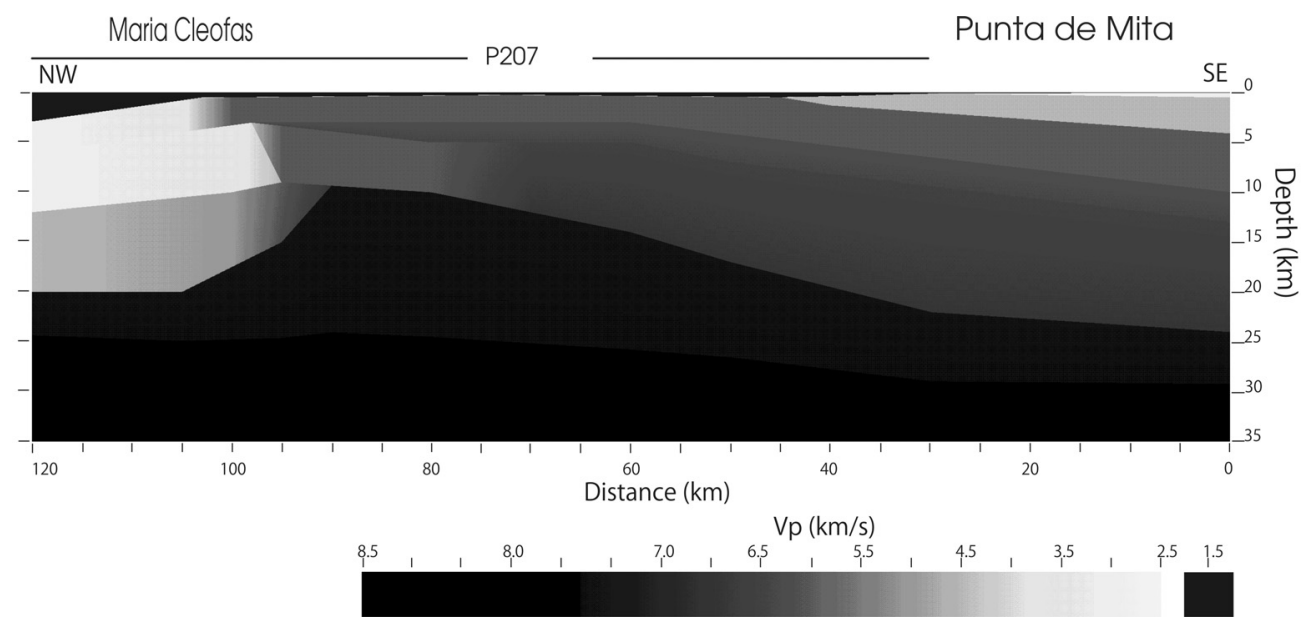

Figura 5. Modelo de la corteza propuesto para el Perfil 207 entre Punta de Mita y la Isla María Cleofas.

\subsection{Estudios 1996 - 1998}

En los años 1996, 1997 y 1998 se realizaron estudios de microsismicidad en el norte y oeste del Bloque de Jalisco motivado por la escasez de trabajos y datos de sismicidad disponibles para esta área, a pesar del conocimiento de la ocurrencia de grandes sismos en este territorio. Los datos obtenidos muestran la gran actividad sísmica que tiene la zona. Además, basándose en la distribución hipocentral y en el estudio de las formas de onda se elaboró una clasificación preliminar de tres zonas sismogénicas. 

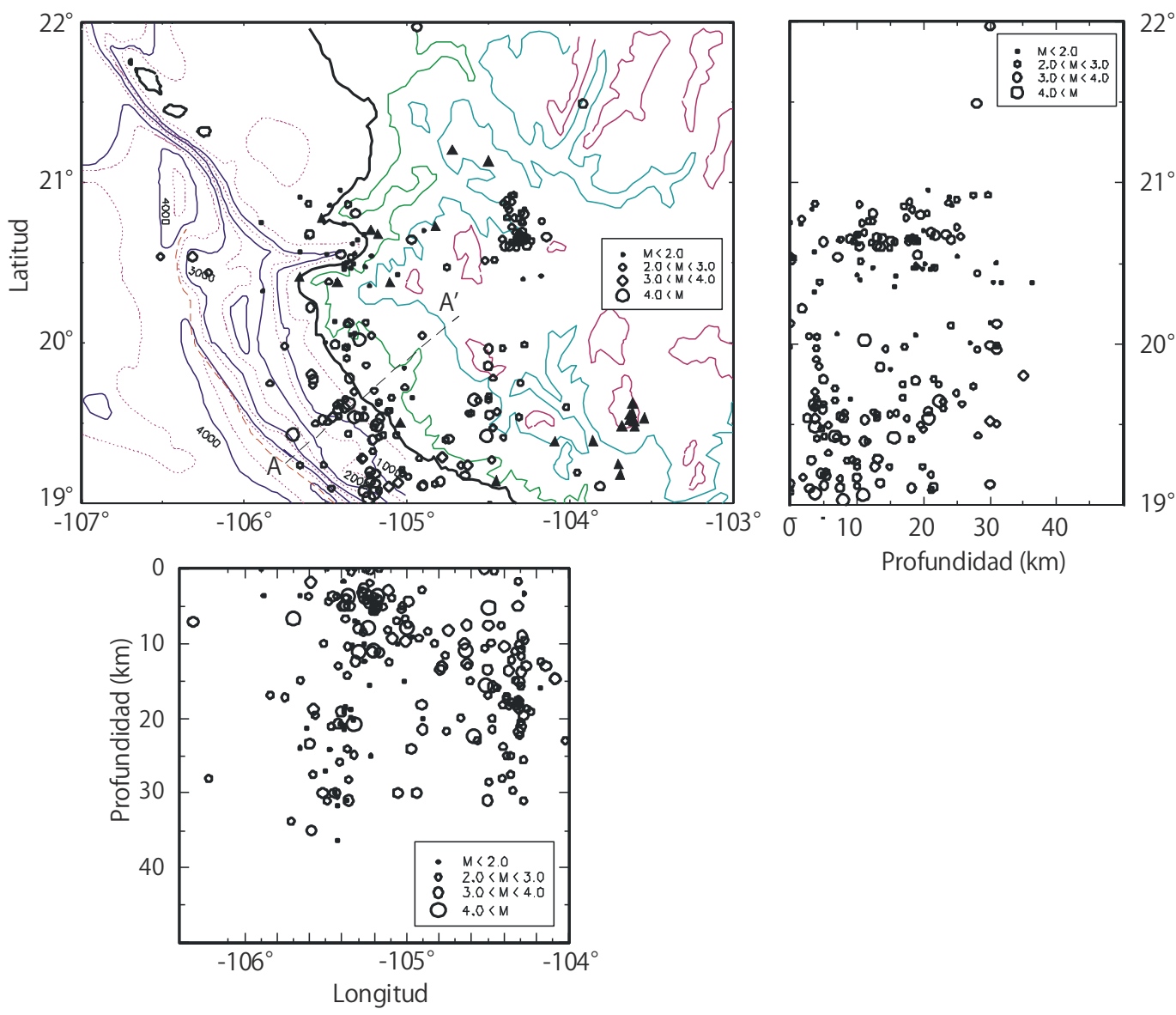

Figura 6. a) Mapa epicentral de los terremotos registrados en el período 1996-1998 en más de dos estaciones. Las estaciones sismológicas se representan por triángulos. b) Sección norte-sur. c) Sección este-oeste.

Para estos estudios se utilizaron cinco estaciones sismológicas Lennartz Mars-88 Le 3D y dos MQ's Spregneter que conformaron la red portátil y de la cual se obtuvieron los datos base del presente estudio de sismicidad. Las estaciones estuvieron operando desde 1996 hasta 1998. Los registros no fueron continuos en todas las estaciones debido a la dificultad en darles mantenimiento y a la insuficiencia de presupuesto. Por lo tanto, los datos recogidos son sólo los equivalentes a unos cuatro meses de registro continuo. Estos datos sísmicos se completaron con datos de la red RESCO, y para algunos casos, la estación de Chamela del SSN, de banda ancha. La posición de las estaciones sismológicas se muestra en las figura 6 y 7 . 
Todos los eventos registrados en tres o más estaciones fueron localizados y se muestran en la figura 6 .

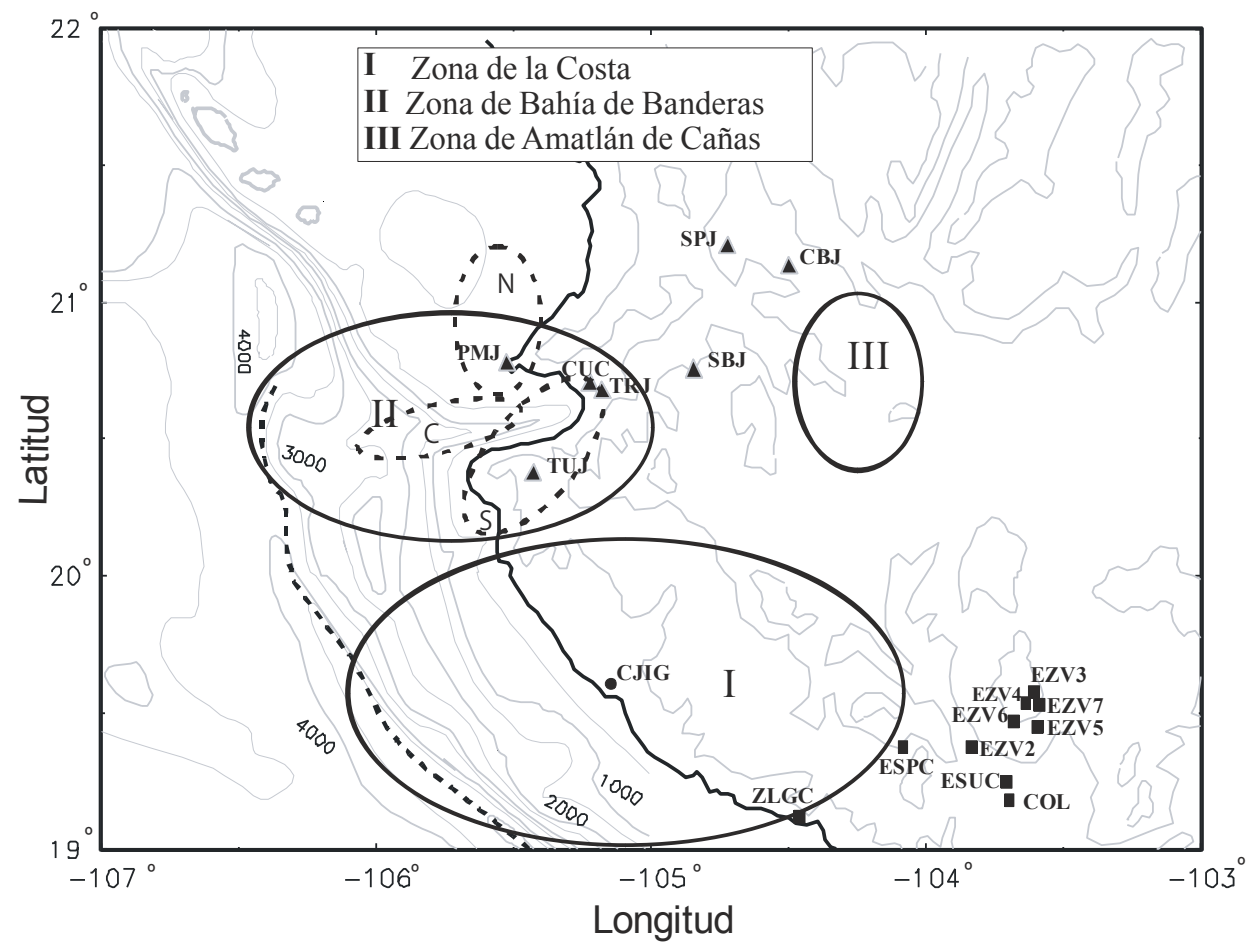

Figura 7. Las tres zonas sismogénicas propuestas y estaciones sismológicas utilizadas.

En la figura 6 se muestran todos los eventos localizados con tres o más estaciones. En el mapa epicentral (Figura 6a) se observa: a) un cese de sismicidad brusco al norte del paralelo 21, b) una franja con muy baja actividad sísmica entre las latitudes $19.7^{\circ}$ y $20.3^{\circ}$, y c) no se registran terremotos al occidente de la fosa de Barra de Navidad. Al sur, sureste de la zona de estudio no fue localizado ningún evento registrado, ya que esta zona está dentro del Graben de Colima que sale fuera del objetivo de este trabajo.

Para analizar la distribución sísmica en función de la profundidad de los eventos se muestran las secciones N-S y E-O que abarcan la región de estudio. La sección norte-sur viene representada en la figura $6 \mathrm{~b}$, en donde se puede apreciar la franja con escasa sismicidad entre las latitudes $19.7^{\circ}$ y $20.3^{\circ}$, y la ausencia de epicentros al norte del paralelo $21^{\circ}$. Los hipocentros se localizan desde la superficie hasta profundidades de $40 \mathrm{~km}$. La figura $6 \mathrm{c}$ representa una sección este-oeste de la región en la que se observan terremotos entre los 15 y $40 \mathrm{~km}$ de profundidad, y desde la trinchera unos $70 \mathrm{~km}$ hacia costa, que difícilmente se puede relacionar con la sismicidad debida al contacto entre la placa oceánica y la continental. 
Se realizó una clasificación de los sismos con base en el análisis de la distribución espacial, obteniéndose diferentes zonas sismogénicas que se caracterizan por tener registros con formas de onda particulares en cada una de ellas.

\subsubsection{Región de la Costa}

Como se observa en la figura 6c, hay eventos costeros a profundidades someras y cerca de la trinchera difíciles de asociar con al contacto de las placas en subducción. Conocemos el trabajo realizado a consecuencia del terremoto de 1995 en las costas de Jalisco y Colima por Pacheco et al. (1997), donde se plantea la razón de la existencia de réplicas a menos de $50 \mathrm{~km}$ de la trinchera Mesoamericana y a una profundidad difícil de asociar a la zona de Wadati-Benioff. Estos autores exponen como posibilidad que estas réplicas, tan cercanas a la trinchera, se producen debido a una carencia de sedimentos con alta presión de poro a profundidades superficiales, de hasta $35 \mathrm{~km}$ (Byrne et al., 1988). Este tipo de actividad sísmica para la zona de subducción de la placa de Cocos ha sido identificada también por Singh et al. (2000). En este último caso, asocian esa actividad a la litosfera oceánica de la placa de Cocos. Estos son los terremotos someros de falla normal, de gran magnitud ( $\mathrm{Mw}$ $>7.0$ ) que ocurren con cierta frecuencia (cuatro de los siete últimos grandes temblores en la placa de Cocos). Este hecho podría implicar que este tipo temblores ocurran también asociados a la subducción de la placa de Rivera bajo el Bloque de Jalisco.

Para caracterizar la actividad sísmica de esta región, analizamos las formas de ondas de todos estos temblores costeros, considerando particularmente la relación $\mathrm{AP} / \mathrm{AS}$, fases refractadas y posibles fases convertidas. Con estas consideraciones se pudo obtener una primera clasificación: Los temblores originados en la litosfera continental, sismos continentales, y aquellos con origen en la litosfera oceánica, sismos oceánicos. Planteándose así la hipótesis que la actividad sísmica cercana a la trinchera se origina en la placa oceánica.

En la figura 8 se muestra un ejemplo de las diferencias significativas en las formas de onda encontradas en el análisis descrito:

- La fase inicial de las ondas directas P y S son de baja frecuencia para las trazas oceánicas, se caracterizan por presentar ondas $\mathrm{P}$ energéticas y en muchos casos claras $\mathrm{P}_{\mathrm{n}}$ 's.

- La primera llegada de las ondas P y S, en el caso de los sismos continentales, es de mayor frecuencia y de baja amplitud. Sus trazas presentan posibles ondas reflejadas convertidas y no se observan ondas refractadas (Núñez-Cornú et al., 2002).

- La razón de amplitudes $\left(\mathrm{A}_{\mathrm{P}} / \mathrm{A}_{\mathrm{S}}\right)$ es claramente mayor para los sismos oceánicos en relación a los sismos continentales (figura 9). 


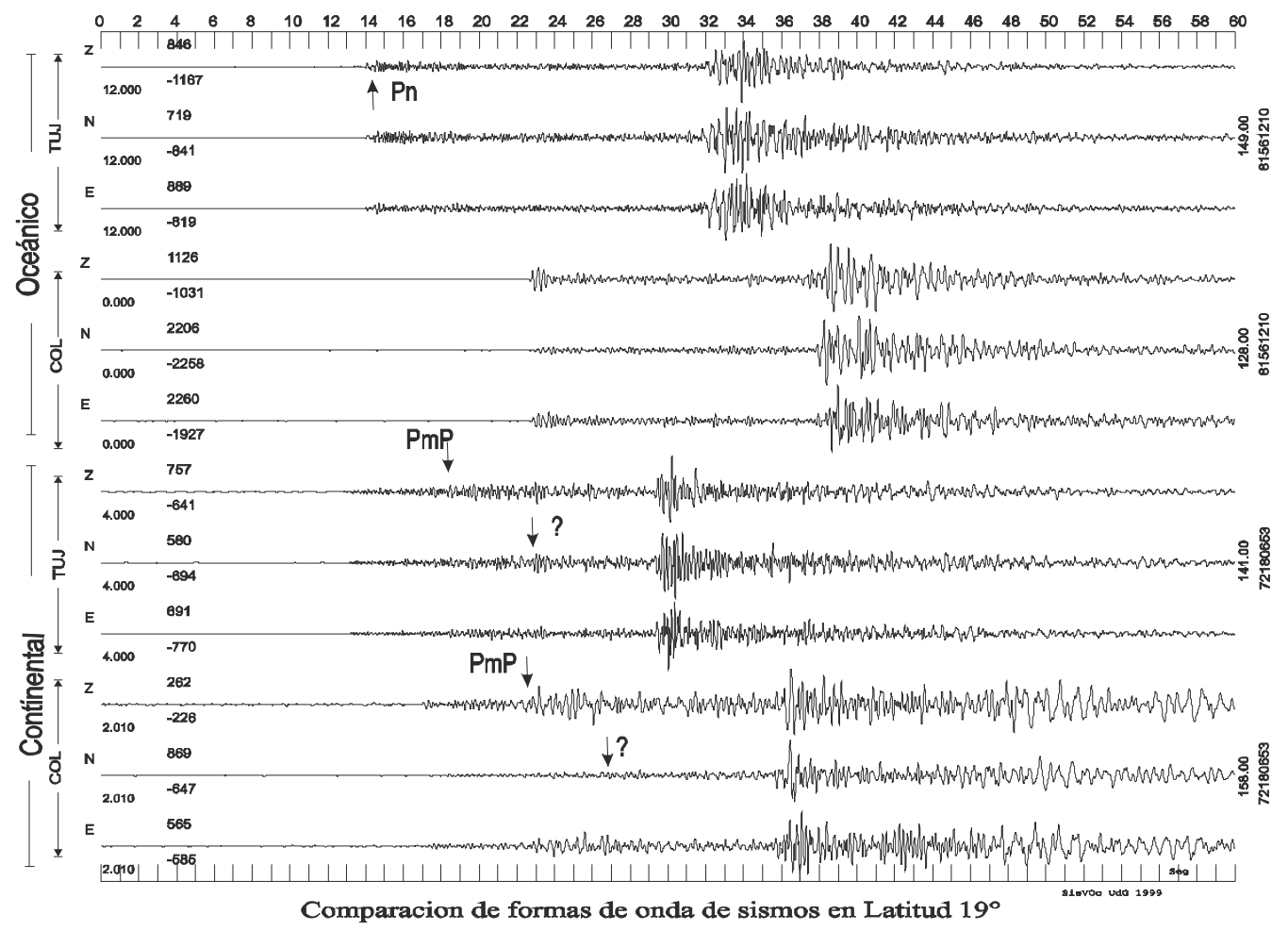

Figura 8. Comparación de formas de onda de eventos continentales y oceánicos registrados en las estaciones TUJ y COL.

Hay 26 terremotos de tipo oceánicos distribuidos desde la trinchera hasta la costa, con profundidades que varían entre los 7 y $30 \mathrm{~km}$ y magnitud $\mathrm{M}_{\mathrm{L}}$ comprendida entre 2.6 y 5.5. Los eventos continentales localizados son 82, cuyos hipocentros se encuentran desde la trinchera hasta a unos $180 \mathrm{~km}$ tierra adentro, con profundidades hasta los $31 \mathrm{~km}$, y magnitud $\mathrm{M}_{\mathrm{L}}$ entre 2.7 y 5.8 (ver figura 9).

En la figura 10 representamos una estimación del ángulo de subducción de la placa de Rivera bajo el bloque de Jalisco. Considerando los eventos continentales se obtiene un ángulo de subducción de $12^{\circ}$, que coincide con la zona de contacto entre las placas convergentes. Se muestra como referencia la línea de los $21^{\circ}$, a mayor ángulo solo se encuentran eventos oceánicos. Estos valores son similares a los obtenidos en los estudios de reflexión y refracción sísmica en el proyecto CORTES96, que se realizó en el 1996 (Dañobeitia et al., 1997) y a los ángulos estimados con datos de la red RESCO para la costa de Colima y sur de Jalisco (Núñez-Cornú \& Sánchez-Mora, 1999). 

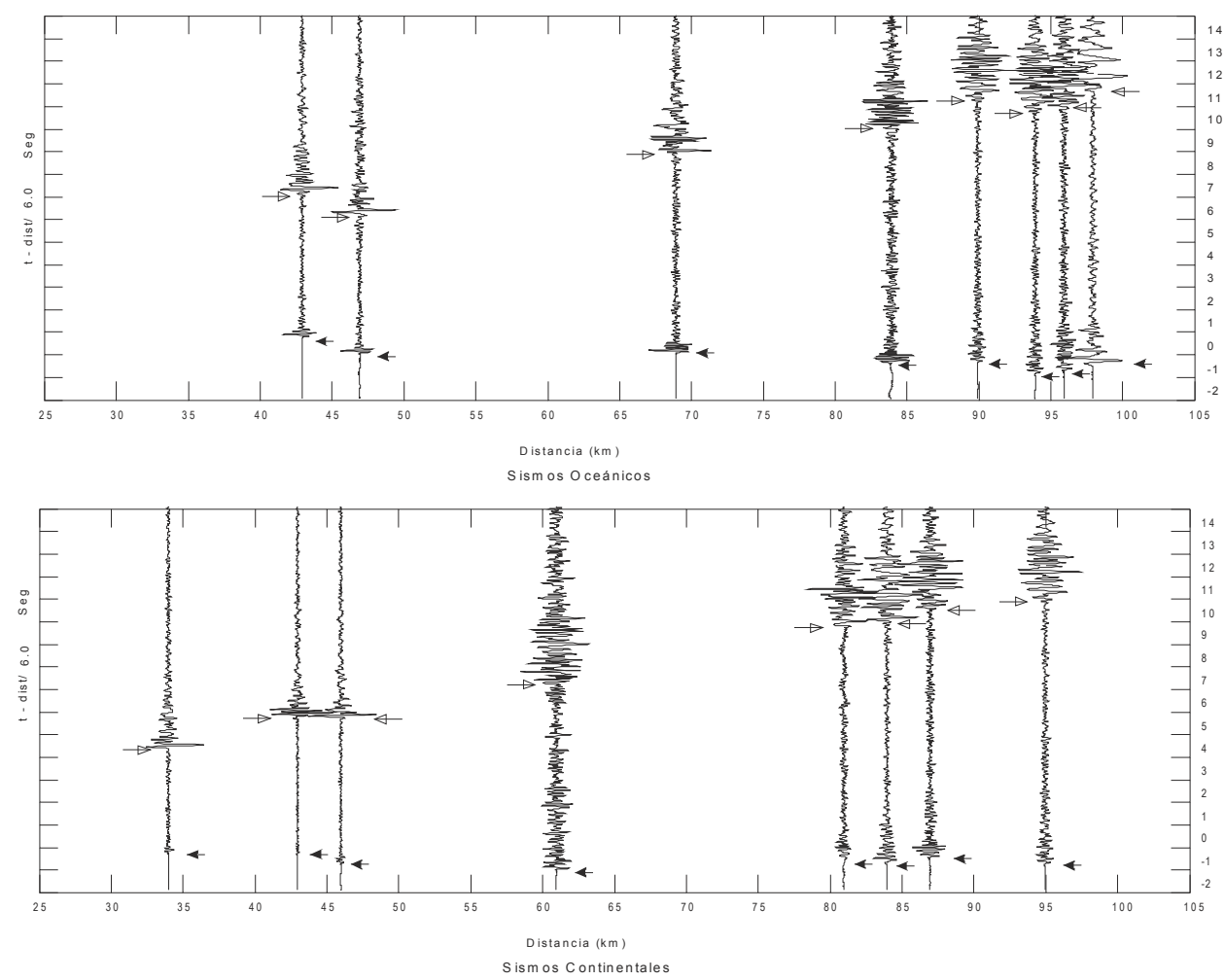

Figura 9. Ensamblajes para sísmicos oceánicos y continentales registrados en la estación TUJ (Sur de la Bahía). Una onda-P muy energética puede ser observada para los sismos oceánicos. Flechas sólidas marcan las ondas-P, flechas huecas marcan las ondas-S, se puede observar una clara diferencia en el radio de la amplitud $\mathrm{P} / \mathrm{S}$ en ambos casos. (Modificado de Núñez-Cornú et al 2002)

Los eventos costeros al sur de la latitud $19.7^{\circ} \mathrm{N}$ están localizados dentro de la zona de ruptura del terremoto de magnitud 8.0 Mw de Octubre de 1995 (Courboulex et al., 1997), pudiendo relacionarse con movimientos de reacoplamiento de placas. Que al norte de esta franja la actividad sísmica sea menor confirma el alto potencial sísmico de la costa norte de Jalisco.

En este estudio se encontró eventos próximos a la trinchera Mesoamericana que son difíciles de relacionar con la zona de Wadati-Benioff de la convergencia de las placas entre Rivera y Bloque de Jalisco. Esta sismicidad se debe a una actividad sísmica en la litosfera oceánica de la placa de Rivera, actividad que ya ha sido documentada para la litosfera oceánica de la placa de Cocos (Singh et al., 2000). 


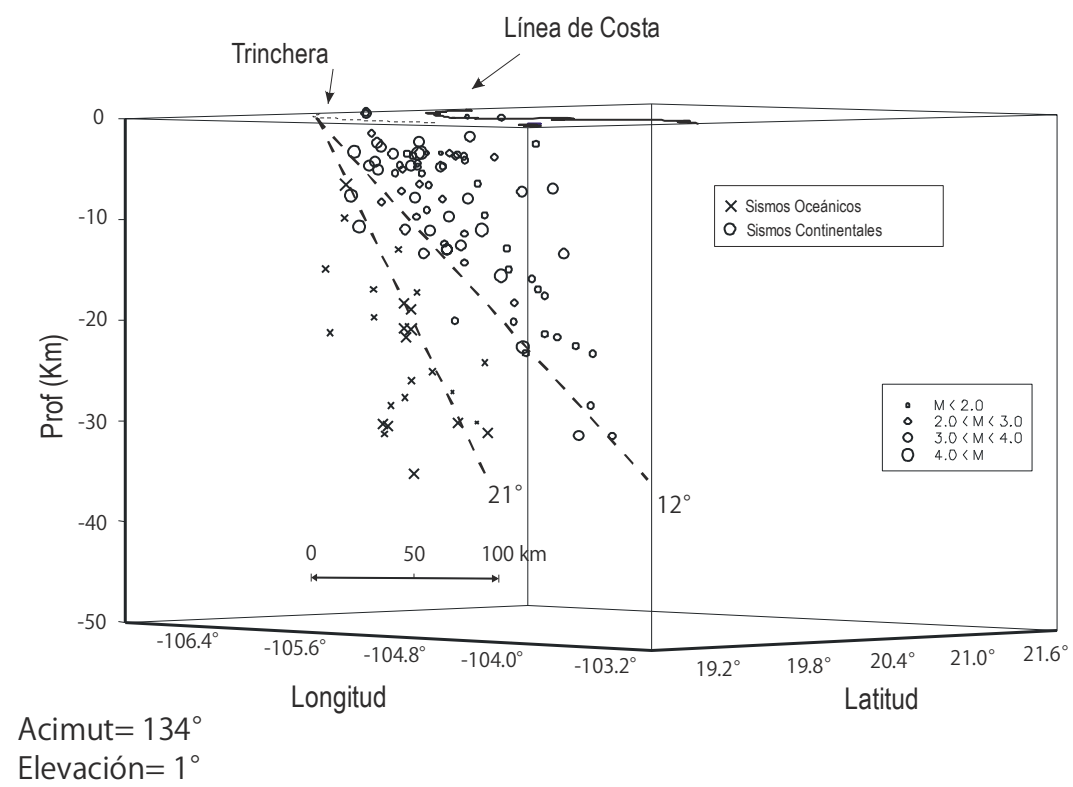

Figura 10. Sismos costeros, tanto de la litosfera oceánica como continental. Los temblores continentales (derecha) tienen un buzamiento de un ángulo de $12^{\circ}$, que sería el correspondiente a la subducción. La otra línea delimita el borde superior de los temblores asociados a la litosfera oceánica (izquierda) con un ángulo de $20^{\circ}$, que podría estar asociado con el borde del manto superior de la placa oceánica. (Modificado de Núñez-Cornú et al 2002)

\subsubsection{Región de Bahía de Banderas}

Esta región comprende la parte terrestre del interior y costas de Bahía de Banderas y el área marítima que alcanza hasta la trinchera Mesoamericana en dirección hacia occidente. En esta región ya se habían definido previamente tres zonas sísmicas, la del norte, centro y sur de la Bahía (Nuñez-Cornú et al., 2002). Se localizaron 40 terremotos con magnitud comprendida entre 1.2 y $4.9 \mathrm{M}_{\mathrm{L}}$, con cuyos datos se realizó el siguiente análisis.

\subsubsection{Zona norte de la Bahía.}

Lo más característico de los eventos localizados en esta zona es que en las señales que llegan a la estación TUJ se observa una gran dispersión de las señales sísmicas. De hecho, pocos temblores localizados al norte de la bahía fueron registrados por esta estación y, sin embargo, la señal llega con claridad a SPJ y SBJ (San Sebastián del Oeste), que se encuentran al oriente y PMJ (Punta de Mita) que se sitúa en el norte de Bahía de Banderas (figura 7). Casi todos ellos ocurren a profundidades 
someras. Este hecho aporta más datos para la hipótesis que sugiere la existencia de una estructura tectónica importante que atraviesa la bahía en dirección E-O (Dañobeitia et al., 1997). Esta posible estructura provoca gran dispersión en las señales sísmicas que la atraviesan, resultado de una región no homogénea y/o muy fracturada. En la figura 11 se muestran los sismogramas de un evento registrado en TUJ y PMJ. En PMJ el temblor se registra mostrando una onda P directa muy impulsiva y una clara $\mathrm{S}$, mientras que en TUJ, la señal cruza la Bahía y llega muy dispersa.

\subsubsection{Zona centro de la Bahía.}

Es en esta zona donde se producen los eventos más profundos, que podrían correlacionarse con la estructura tectónica comentada en el párrafo anterior, que marca el límite norte del Bloque de Jalisco, "Borde de Banderas", que hoy en día está aun sin delimitar y que podría prolongarse hacia el este uniendo la zona sísmica del centro de la Bahía con la de Amatlán de Cañas-Ameca. Es en esta zona donde se encuentra el cañón submarino que atraviesa la Bahía de este a oeste, que se ha propuesto como prolongación marítima del Graben del Río Ameca (Fisher, 1961, Johnson \& Harrison, 1990). Reafirmando esta hipótesis Álvarez (2001) realizó una campaña de ecosondeos en la parte del cañón submarino de la Bahía encontrando una alta reflectancia, posiblemente debido a la composición granítica, con gran cantidad de picos y cañones que llegan hasta los $1400 \mathrm{~m}$ de profundidad. La falta de sedimentos en las profundidades es significativo de una zona dinámicamente activa.

\subsubsection{Zona sur de la Bahía.}

Esta zona está definida por los eventos que ocurren en la parte suroriental de la bahía. Estos incluyen los sismos del área de Puerto Vallarta, el Tuito y la costa sur de la bahía. Todos estos eventos son superficiales y se pueden correlacionar con rasgos morfoestructurales, lo que implica que hay estructuras locales continentales activas y, por lo tanto, potencialmente peligrosas. Son este tipo de temblores los que se producen continuamente en los enjambres registrados en la estación TUJ; entre estos enjambres se pueden observar familias de terremotos. Estos terremotos se encuentran localizados en un radio de $60 \mathrm{~km}$ de la estación TUJ. 

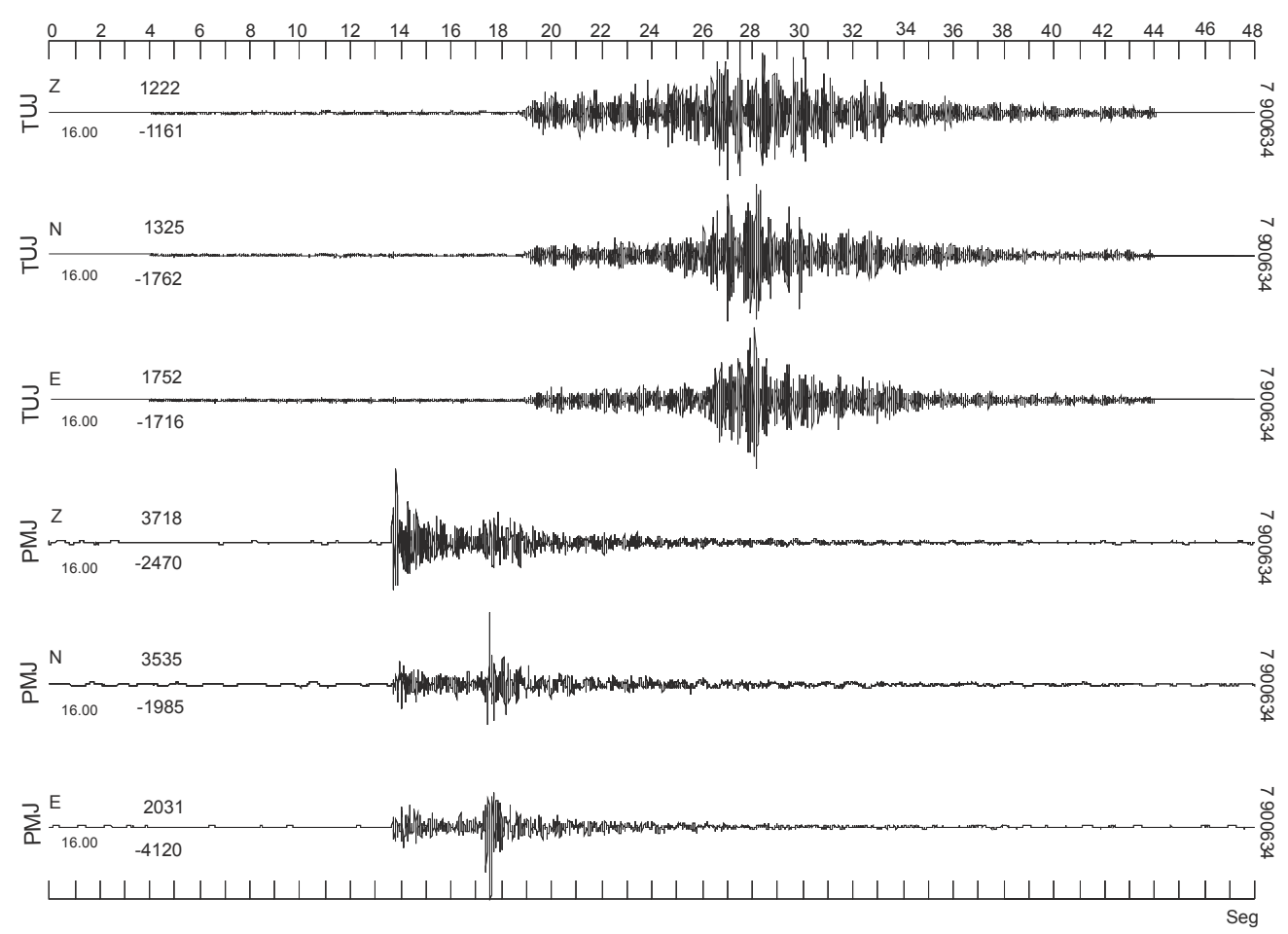

Figura 11. Terremoto registrado en la zona norte de Bahía de Banderas. Las tres primeras trazas son las tres componentes del registro de TUJ (sur de la bahía). Las tres últimas trazas son las registradas por PMJ (norte de la bahía).

\subsubsection{Región de Amatlán de Cañas.}

Esta región se encuentra entre Amatlán de Cañas y Ameca, lindando en su extremo norte con el graben de Tepic-Zacoalco (región III). La sismicidad es continental y los eventos no sobrepasan los $35 \mathrm{~km}$ de profundidad, con lo cual la sismicidad se distribuye en todo el grosor de la corteza continental. Durante el período de funcionamiento de las estaciones sismológicas se pudieron localizar 49 eventos, con valores de magnitud comprendidos entre 2.9 y $5.3 \mathrm{M}_{\mathrm{L}}$. De este total, 24 temblores se produjeron en el enjambre de Marzo de 1998 durante un periodo de 6 días. 


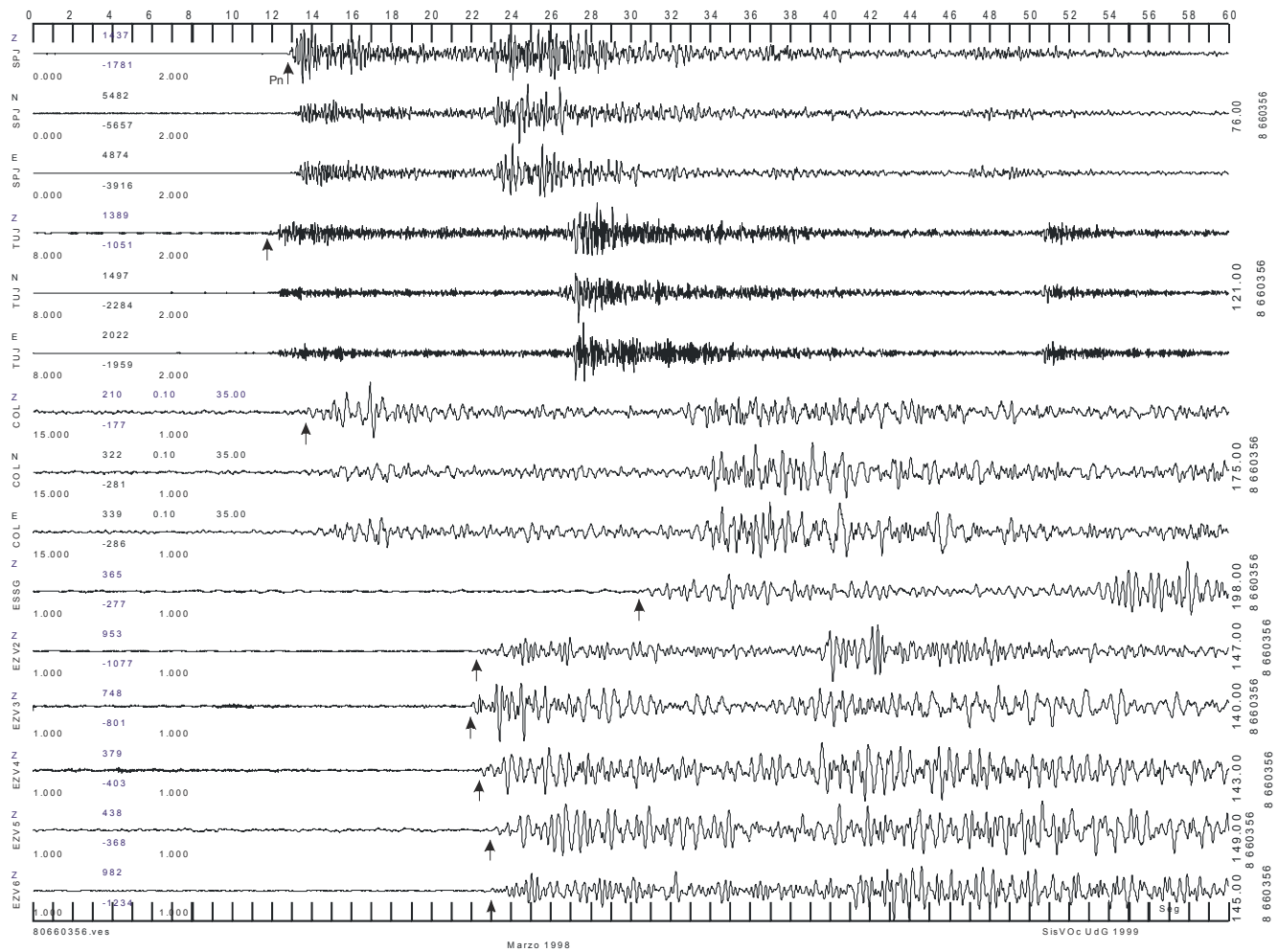

Figura 12. Terremoto ocurrido en el enjambre de Marzo de 1998 en la región III (Amatlán de Cañas). Las flechas indican la fase Pn. Fue registrado por la red portátil y por las estaciones de la red RESCO.

En la figura 12 se muestran los sismogramas de uno de los eventos ocurridos en el enjambre de Marzo de 1998 y que se localizó a $121 \mathrm{~km}$ de TUJ y a $76 \mathrm{~km}$ de SPJ (San Pedro Lagunillas). En SPJ existe una fase inicial que no parece ser la onda $\mathrm{P}$ directa, más bien una Pn, la cual se observa claramente en los registros de TUJ. La aparición de ondas refractadas a distancias pequeñas del hipocentro indican una fuerte discontinuidad o la posible existencia de una discontinuidad de Conrad.

\subsubsection{Modelo}

Para resaltar la distribución de los hipocentros se muestran dos figuras proyectadas en tres dimensiones con perspectivas diferentes. En la figura 13a los temblores relacionados con la litosfera continental (círculos) se encuentran en una franja estrecha entre la trinchera y la costa. Con esta orientación estos eventos se ajustan para formar un alineamiento, pudiendo relacionarlo con el plano que define la actividad sísmica debido al contacto entre placas (zona de Wadati-Benioff). 

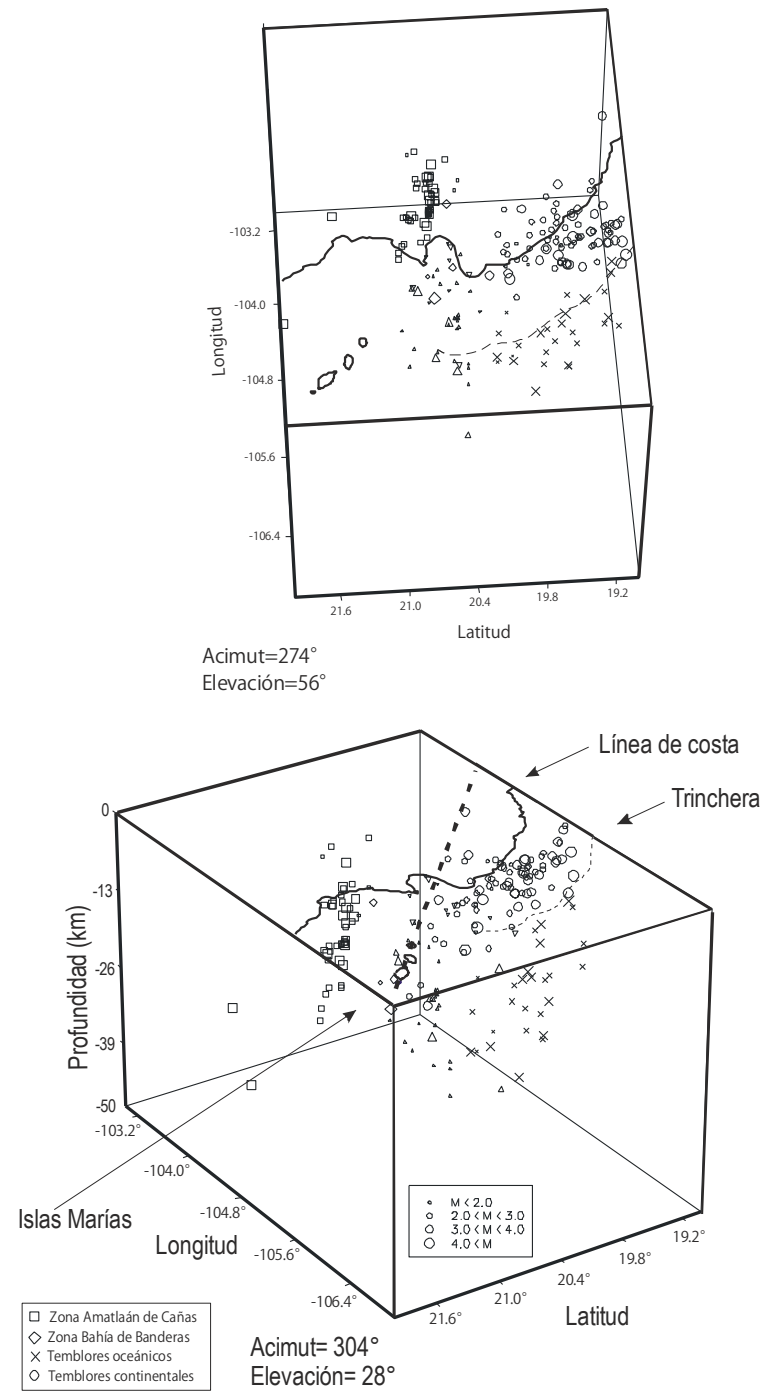

Figura 13. Perspectiva de la distribución sísmica en tres dimensiones de los hipocentros separados en los cuatro tipos de sismos caracterizados. (Modificado de Rutz y Núñez-Cornú, 2004)

Separados de estos eventos continentales y por debajo de la trinchera, se encuentran los temblores asociados a la litosfera oceánica (cruces). Si se traza una línea uniendo las Islas Marías con el límite de actividad sísmica continental costera y el 
volcán de Fuego (Colima), todos los eventos costeros quedan al oeste y solamente la región de Amatlán de Cañas (cuadrados) se localiza al este de esta línea. Esta vista podría indicar la dirección de una subducción oblicua (figura 14) a lo largo de la línea discontinua, lo que implica la posibilidad de un movimiento relativo de la placa de Rivera con respecto al bloque de Jalisco en dirección sureste. En la figura $13 \mathrm{~b}$ la vista es desde el suroeste y nos muestra las mismas características mencionadas como son los límites de sismicidad y el agrupamiento a los lados de la trinchera de los temblores de origen continental y oceánico.

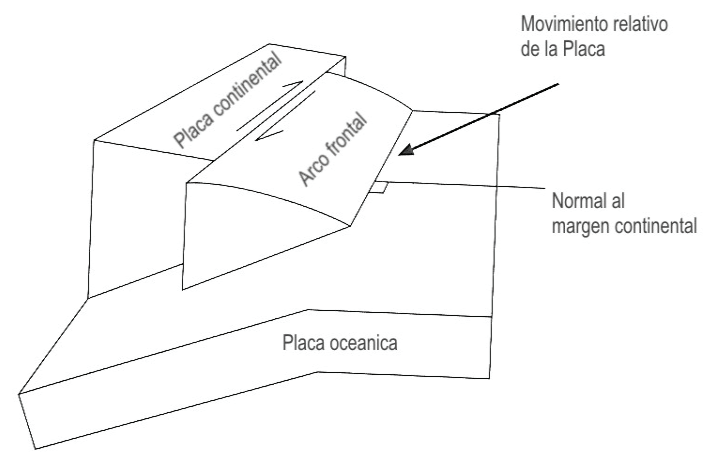

Figura 14. Perspectiva de la distribución sísmica en tres dimensiones de los hipocentros separados en los cuatro tipos de sismos caracterizados. (Modificado de Rutz y Núñez-Cornú, 2004)

\subsection{Estudios 2000 - 2003}

En el año 2000 comenzó un proyecto conjunto entre la Universidad de Guadalajara y la Unidad Estatal de Protección Civil de Jalisco (PCJal) para llevar a cabo la primera fase de la red sismológica estatal, RESJAL, con la instalación de estaciones permanentes en la zona del Volcán de Fuego y de Bahía de Banderas. Durante los años 2001 y 2002 se fueron instalando paulatinamente las seis estaciones telemétricas (Kinemetrics Everest 24bit, 6ch; sensor LE3D 1Hz) pertenecientes a Protección Civil y tres estaciones sismológicas áutónomas (Lennartz MarsLite; sensor LE3D 1Hz) de la Universidad de Guadalajara. En febrero de 2003 el Gobierno del Estado de Nayarit contribuyó a la red sismológica de la zona con la instalación de una estación portátil en el volcán Ceboruco para el seguimiento de su actividad volcánica. No es hasta mediados del 2003 que se optimiza el funcionamiento de la red sismológica. Se consigue ajustar los parámetros de las estaciones para una detección y almacenamiento de sismos menores, con magnitud local inferior a cero. Adicionalmente se contó con los registros de la red RESCO para los eventos localizados por la RESJAL. 


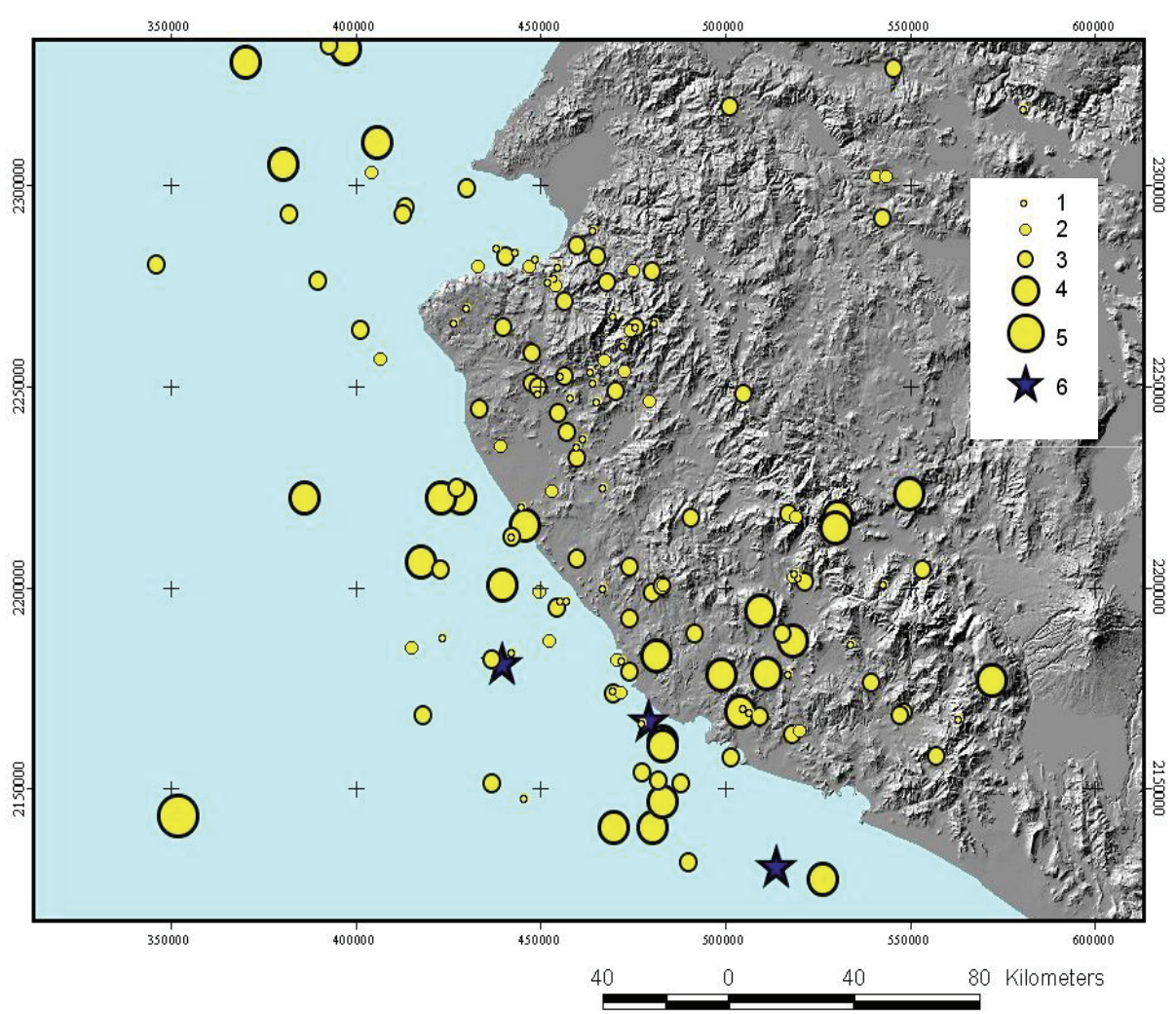

Figura 15. Sismicidad localizada por el SisVOc en los años 2001 y 2002.

La red sismológica de Jalisco RESJAL empezó a instalarse a finales de 2001 y no es hasta finales de 2002 que se finaliza la primera fase de su instalación. En este periodo de tiempo se localizaron entre las latitudes $19^{\circ} \mathrm{N}-22^{\circ} \mathrm{N}$ y longitudes $107^{\circ} \mathrm{W}$ $104^{\circ} \mathrm{W} 211$ temblores con magnitud local entre 0 y 4.7 .

La distribución espacial de los hipocentros del periodo 2001-2002, que se muestra en la figura 15 es muy parecida a la ya registrada en 1998 (Figura 6). 


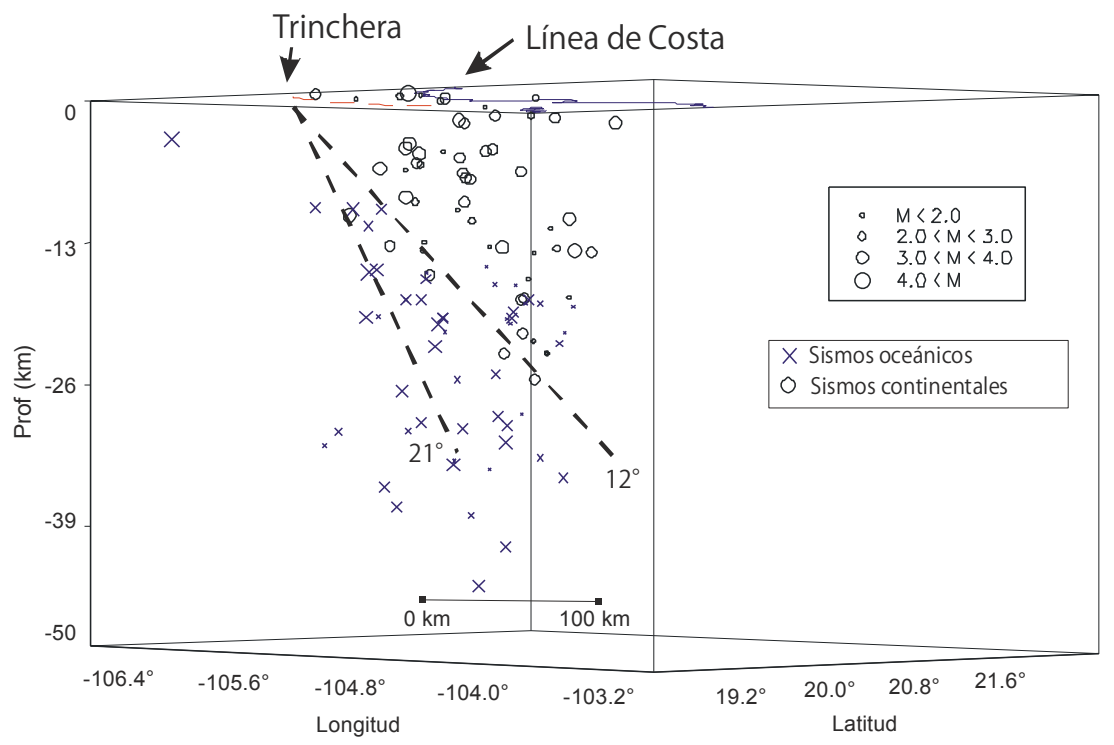

Figura 16. Perfil perpendicular a la trinchera de la sismicidad costera localizada por el SisVOc en los años 2001 y 2002.

Al norte de la latitud $21^{\circ} \mathrm{N}$ la sismicidad es muy escasa. Hay actividad sísmica de baja magnitud en la zona de Bahía de Banderas y de magnitud considerable en la costa sur de Jalisco y en la zona de Amatlán de Cañas-Ameca la sismicidad detectada es menor. En general los patrones sísmicos observados en las tres regiones (Figuras 16 y 17) son similares a los observados para el período $1996-1998$.

De enero a septiembre del 2003 se localizaron 435 temblores (Figura 18) entre las coordenadas $22^{\circ}(2,435,000) \mathrm{N}-19.5^{\circ}(2,156,000) \mathrm{N}$ y $106^{\circ}(396,000) \mathrm{W}-104^{\circ}$ $(605,000) \mathrm{W}$, con magnitud local comprendida entre 0.0 y 5.0 . Se redujo la zona de estudio a la zona de Bahía de Banderas hasta el Valle de Tomatlán y a la zona de Amatlán de Cañas-Ameca. Se observa nuevamente actividad en el área de Amatlán de Cañas

El último trimestre de 2003 no funcionaron las estaciones BSSJ, MCUJ y temporalmente YELJ y CORJ debido a falta de medios para su mantenimiento. En ese período de tiempo se registraron enjambres con un total de 400 temblores de baja magnitud en la estación de AGUJ y parte en YELJ que no pudieron ser localizados por ser las únicas estaciones que los registraron.

A partir del análisis de la actividad sísmica localizada en la región de la Bahía durante el año 2003 registrada con una red regional de 7 estaciones sismológicas en la zona de Bahía de Banderas, se identificaron series de temblores con funciones de onda muy parecidas. 


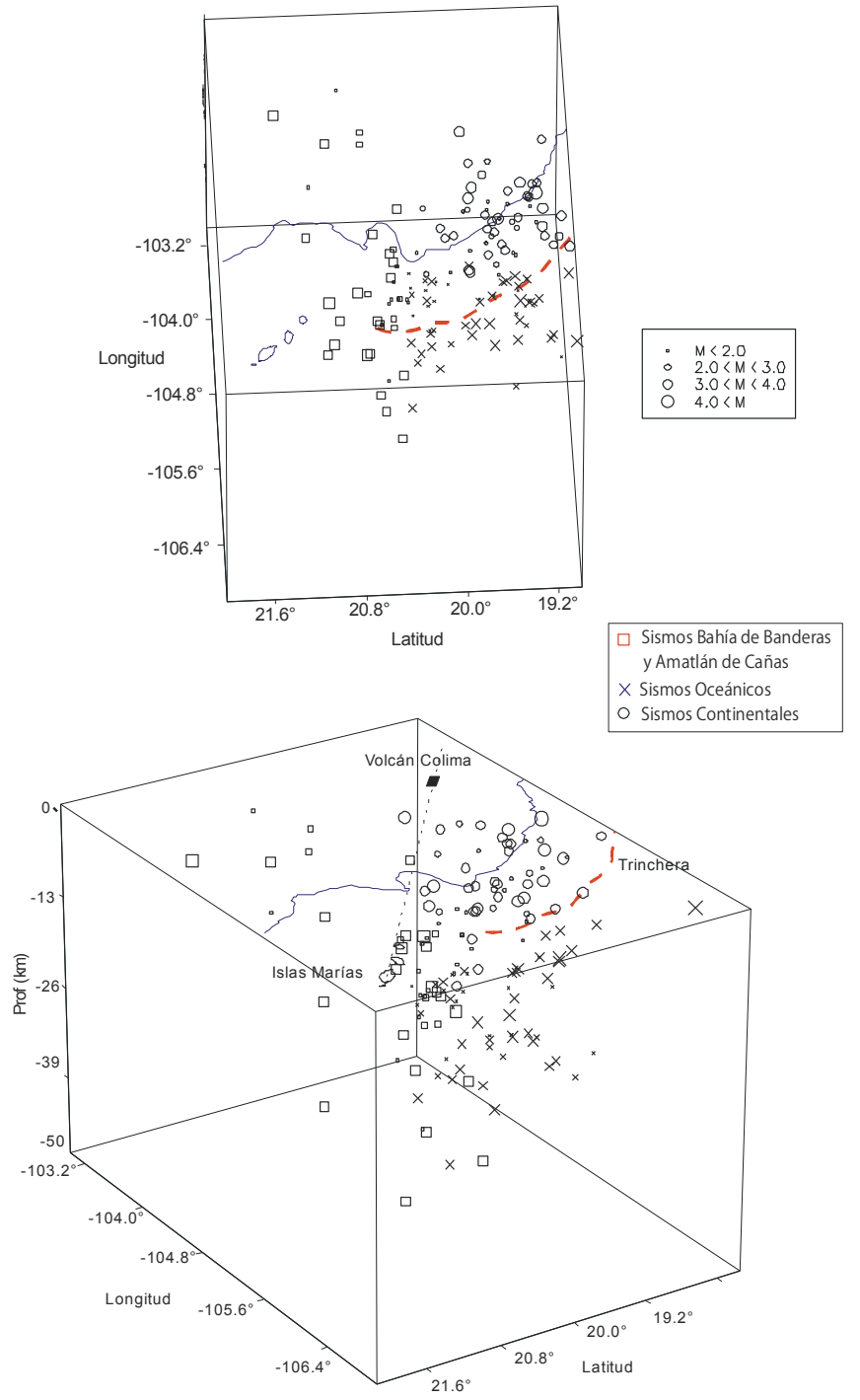

g en 2001-2002 de de los diferentes tipos de sismos caracterizados.

Para definir similitud entre eventos sísmicos y poderlos clasificar en familias se aplicó el método de "correlación cruzada (cross-correlation)" con las llegadas de las ondas $\mathrm{P}$ y $\mathrm{S}$ de los datos localizados. 


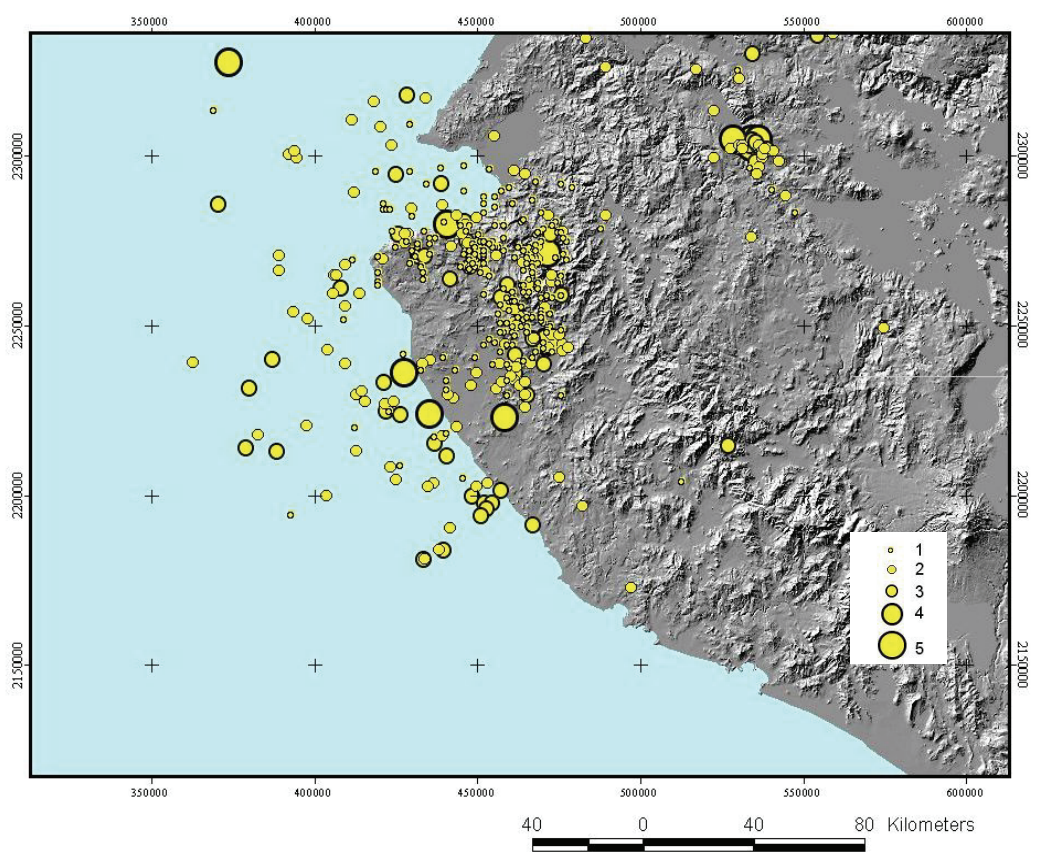

Figura 18. Sismicidad localizada por el SisVOc en el año 2003.

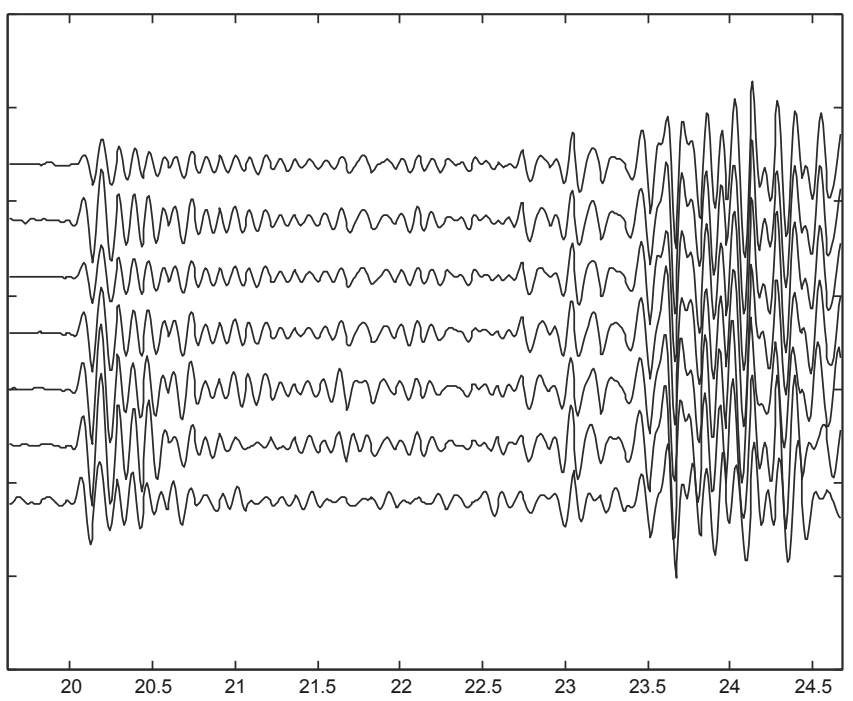

Figura 19. Sismogramas correspondientes a una familia. 
De los sismogramas de la estación MCUJ se identificaron 19 familias que cuentan con 3 a 14 epicentros (Figura 19). Esto ha permitido identificar estructuras tectónicas activas en la zona de la Presa de Cajón de Peñas, en el Municipio de Tomatlán, en la zona de Amatlán de Cañas-Ameca y en el centro de Bahía de Banderas (Rutz, 2007).

\subsection{El Terremoto de Armería (22 enero 2003)}

El 21 de junio del 2003 a las 20:06 (hora local) ocurrió un terremoto frente a las costas de Colima. Inicialmente las primeras localizaciones de fuentes internacionales indicaron que el epicentro había tenido lugar en lo que se conoce como el Gap de Colima, sin embargo resultados preliminares de RESCO complementados con los datos de la RESJAL y la red autónoma del SisVOc indicaron que no fue así; la mejor solución obtenida para el Terremoto fue $02: 06.30 .18 .1658^{\circ} \mathrm{N},-104.0895^{\circ} \mathrm{W}$, $-5.0 \mathrm{~km}$. Utilizando el método de polaridades de primeros arribos se obtuvo un mecanismo focal de falla inversa donde el plano de falla plano de falla con acimut de $259^{\circ}$, buzamiento de $41^{\circ}$ y deslizamiento de $88^{\circ}$ (Figura 20).

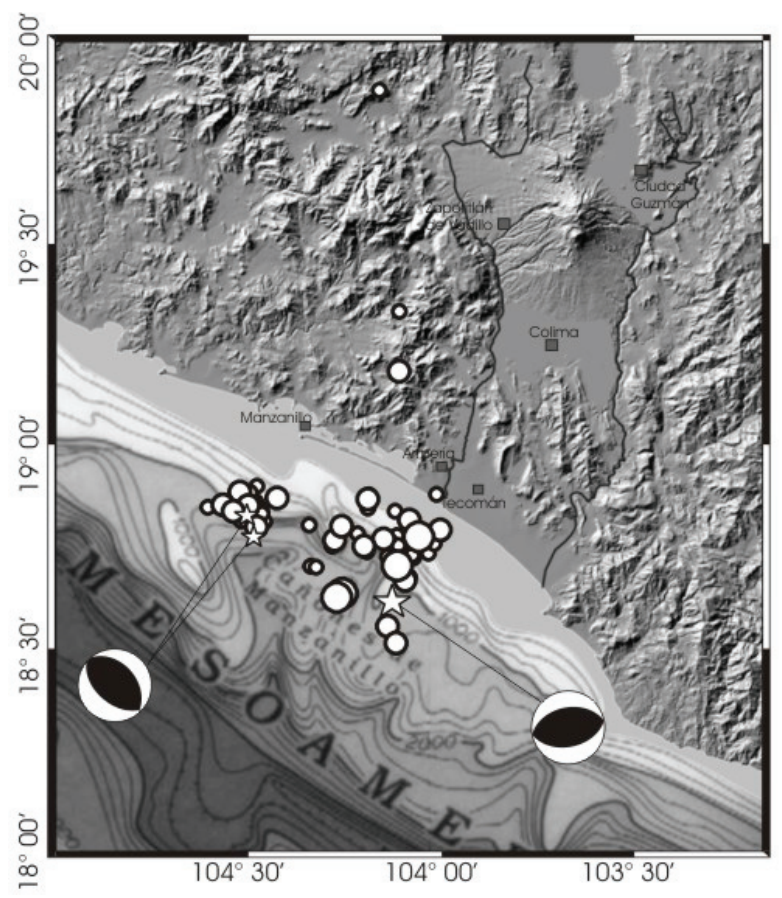

Figura 20. Replicas localizadas para las primeras 72 horas usando datos de RESCO, RESJAL y SisVOc. Mecanismo focal para el Terremoto y las dos réplicas mayores (mecanismo conjunto). 
Con los datos de estas tres redes fue posible hacer un estudio de las réplicas del evento ocurridas en las primeras 72 horas inmediatas posteriores al Terremoto utilizando más de 18 estaciones para localizar las réplicas.

Primeramente se obtuvo un modelo de velocidades (VJB02) utilizando datos de estudios de estructura de corteza realizados en la región. Para el estudio se utilizaron los eventos registrados en ambas redes (72 eventos) los cuales tienen una magnitud local mayor o igual a 3.0. La distribución epicentral de las réplicas localizadas claramente indica que el evento ocurrió en la parte suroeste del Bloque de Jalisco, fuera del Graben de Colima y consecuentemente del Gap de Colima. Las réplicas están concentradas en dos áreas (Fig. 20), la mayor parte sobre en el área epicentral del terremoto (TAR), distribuidas primordialmente en una dirección $\mathrm{E}-\mathrm{O}$, y otras en el área epicentral del Terremoto de 1995 (T95). La distribución en profundidad de los hipocentros se muestra en la figura 21, la mayor parte de ellos a menos de $16 \mathrm{~km}$ de profundidad.

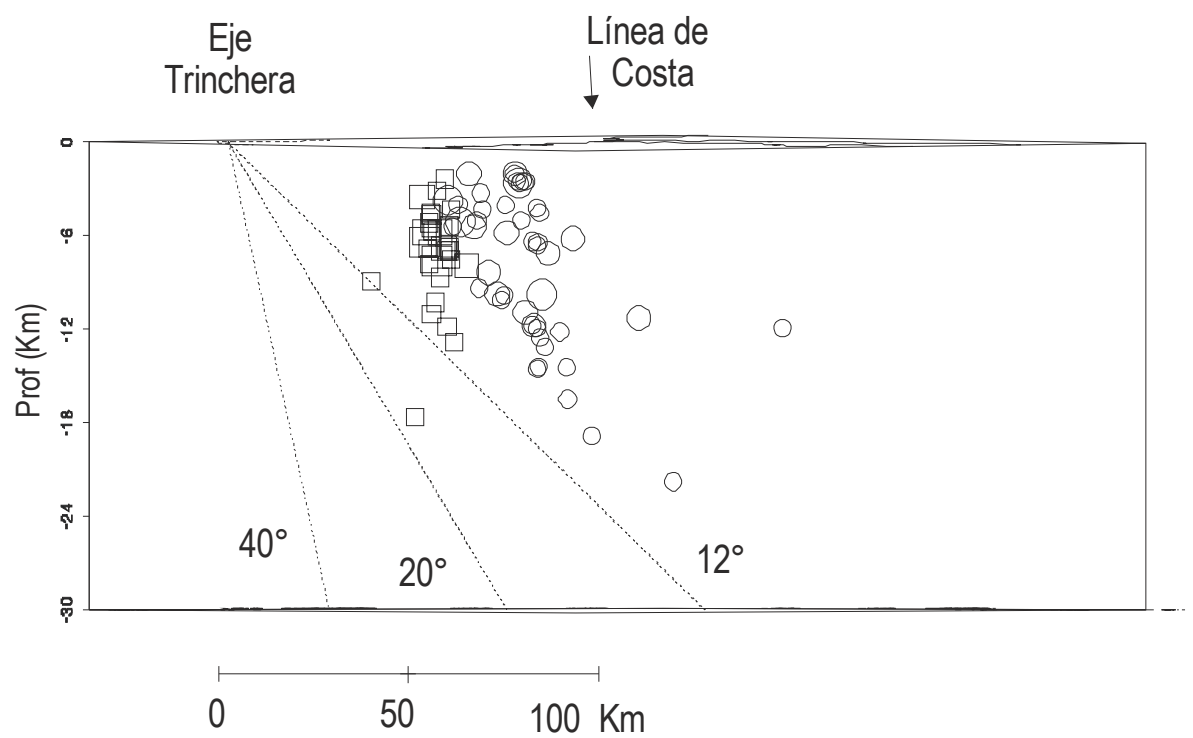

Figura 21. Perfil perpendicular a la trinchera de las replicas localizadas para las primeras 72 horas. TAR círculos; T95 cuadros. (Modificado de Núñez-Cornú et al 2004)

La orientación del mecanismo focal del evento principal coincide con la distribución hipocentral de las réplicas localizadas en este trabajo para las primeras 72 horas (Figuras 21 y 22), esto indica que el terremoto fue un evento continental de falla inversa, no se tiene antecedentes para este tipo eventos en esta región. 


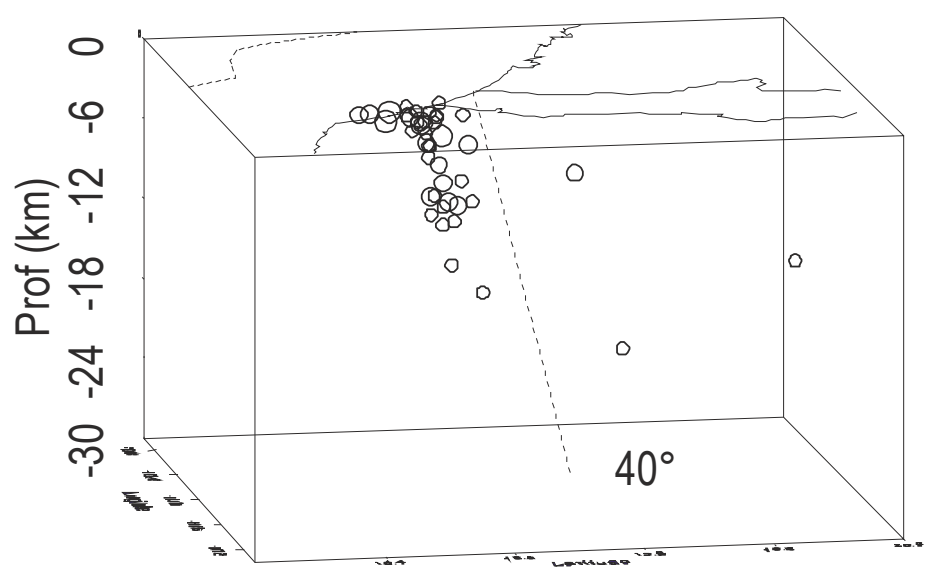

Figura 22. Proyección de las replicas sobre un acimut de $350^{\circ}$. (Modificado de NúñezCornú et al 2004)

\section{Conclusiones}

A partir de la revisión y reevaluación de la sismicidad histórica en la región de Jalisco y los estudios puntuales regionales recientes, se observa que prácticamente en toda la extensión y bordes del Bloque de Jalisco existen altos niveles de sismicidad lo que representa Peligro Sísmico que debe ser adecuadamente evaluado. Actualmente el Peligro Sísmico mayor estaría asociado al Gap Sísmico de la Costa Norte de Jalisco capaz de generar un terremoto de $\mathrm{M}=8.0$ y posiblemente un Tsunami. Sin embargo terremotos recientes, como el de Armería (2003) y las Islas María (1948), muestra la existencia de terremotos intraplaca de magnitud media $(6.9<\mathrm{M}<7.4)$ que pueden ser muy destructivos. Existen también grandes terremotos históricos al interior de la región (Figura 3) que han causado grandes destrozos (el último de ellos en 1921), para los cuales deben identificarse su génesis. La correcta evaluación del Peligro Sísmico en la región solo se puede realizar mediante el estudio continuo de la sismicidad en la región.

A partir de 2004 PCJal dejó de apoyar el mantenimiento de la RESJAL, excepto parcialmente las estaciones ubicadas en el Volcán Colima durante las explosiones del 2005 , por este motivo no se pudo dar continuidad al estudio de la sismicidad en la región.

En el 2010 el Centro de Sismología y Volcanología de Occidente de la Universidad de Guadalajara con el financiamiento de CONACyT-FOMIXJal (2008-96538) empezó a instalar una red telemétrica que cubrirá todo el Estado de Jalisco, lo que permitirá continuar el estudio del Peligro Sísmico en Jalisco. 


\section{Referencias bibliográficas}

ÁlVAREZ, R (2001). "Bahía de Banderas: Posible límite tectónico del Bloque de Jalisco", GEOS, 21, 3, 212.

BARTOLOMÉ, R., Evolución tectónica del margen continental oeste de Mexico: Fosa Mesoamericana y Golfo de California (CORTES-P96). (2002), Tesis Doctoral, Universidad de Barcelona, http://www.minas.upm.es/fundacion/ jgs/trabajos/ 03a01.htm

BARTOLOME, R., DAÑOBEITIA, JJ, MICHAUD, F., CÓRDOBA, D., DELGADOARGOTE, L., (2011).Imaging the seismic crustal structure of the western Mexican margin between $19^{\circ} \mathrm{N}$ and $21^{\circ}$. Pure and Applied Geophysics, 168.

COURBOUlEX, F., SINGH, S.K., PACHECO, J.F. \& AMMON, C.J. (1997), "The 1995 Colima-Jalisco, Mexico, earthquake (Mw 8): A study of the rupture process", Geophys. Res. Lett., 24, 1019-1022.

DAÑOBEITIA, J. J., CÓRDOBA, D., DELGADO-ARGOTE, L. A., MICHAUD, F., BARTOLOMÉ,R., FARRÁN, M., and CORTES-P96 Working Group (1997), Expedition gathers new data on crust beneath Mexican West Coast. EOS Trans. Am. Geophys. Union 78 (49), 565-572.

EISSLER, H.K. AND MCNALLY K.C. (1984), "Seismicity and tectonics of the Rivera Plate and implications for the 1932 Jalisco, Mexico, earthquake", J. Geophys. Res. 89(B6): 4520-4530.

FISHER ROBERT, L. (1961), "Middle America Trench: topography and structure”, Geol. Soc. Am. Bull., 72, 703-720.

JOHNSON, C.A. \& HARRISON, C.G.A. (1990), "Neotectonics in Central Mexico", Phys. Earth Plan. Int., 64, 187-210.

PACHECO J., SINGH, S.K., DOMÍNGUEZ, J., HURTADO, A., QUINTANAR, L., JIMÉNEZ, Z., YAMAMMOTO, J., GUTIÉRREZ, C., SANTOYO, M., GUZMÁN, M., KOSTOGLODOV, V., REYES, G. AND RAMÍREZ, C. (1997). The october 9, 1995 Colima-Jalisco, earthquake (Mw 8): An aftershock study and a comparison of this earthquake with those of 193. Geophys. Res. Lett., 24, 2223-2226.

NÚÑEZ-CORNÚ, F.J., M. RUTZ, F.A. NAVA, G. REYES-DAVILA, C. SUÁREZPLASCENCIA (2002) Characteristics of Seismicity in the Coast and North of Jalisco Block, MEXICO. Phys. Earth. Plant. Int, 132,1/3, 141-155.

NÚÑEZ-CORNÚ, F. J., M. RUTZ LÓPEZ, VICTOR MÁRQUEZ RAMÍREZ, C. SUÁREZ-PLASCENCIA, ELIZABETH TREJO GÓMEZ (2011). A reassessment of the source region of 2003 Armería, México, Earthquake, using an enhaced data set. Pure and App Geoph. 168, 1293-1302.DOI 10.1007/s00024-010-0178-x.

NÚÑEZ-CORNÚ, F.J., G. A. REYES-DÁVILA, M. RUTZ LÓPEZ, R. TREJO-GÓMEZ, M. A. CAMARENA-GARCIA, AND C.A. RAMÍREZ-VAZQUEZ.(2004) The 2003 Armería, México Earthquake (Mw 7.4): Mainshock and early aftershocks. Seismological Research Letters. 75,6,. 506 - 605. 2004. ISSN 0895-0695

RUTZ LÓPEZ Marta (2001). Microsismicidad del noroeste del Bloque de Jalisco (México). Aplicación a la Sismotectónica y peligrosidad sísmica de la zona. Tesis, Universidad de Granada. España. (Mayo 2001)

RUTZ LÓPEZ, Marta (2007). Peligro Sísmico en Bahía de Banderas (2007). Tesis Maestría. Posgrado en Geofisica. Universidad de Guadalajara (Mayo 2007). 
RUTZ LÓPEZ M., F. Núñez-Cornú (2004). Sismotectónica del norte y oeste del Bloque de Jalisco usando datos sísmicos regionales. GEOS, 24, 3.

SINGH, S.K., L. ASITZ AND J. HAVSKOV (1981), "Seismic gaps and recurrence periods of large earthquakes along the Mexican subduction zone: A reexamination", Bull. Seism. Soc. Am., 71, 3, 827-843.

SINGH, S.K., KOSTOGLODOV, V., PACHECO, J.F. (2000), "Interslab earthquakes in the subducting oceanic plates below Mexico"p. GEOS, 20, 347. 